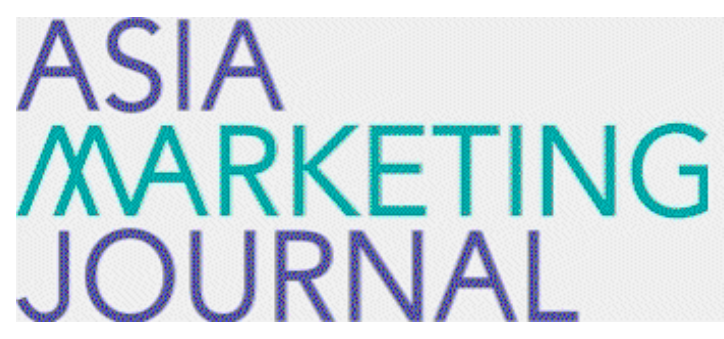

ASIA MARKETING JOURNAL

Volume 4 | Issue 2

Article 5

6-1-2002

\title{
인지-감소성소구의 광고평가에 대한 사전지식과 관여도의 상대적 \\ 역할
}

Yun Yong Hwang

Kwang Jin $\mathrm{Na}$

Follow this and additional works at: https://amj.kma.re.kr/journal

Part of the Marketing Commons

\section{Recommended Citation}

Hwang, Yun Yong and Na, Kwang Jin (2002) "인지-감소성소구의 괗고평가에 대한 사전지식과 관여도의 상 대적 역 할," Asia Marketing Journal: Vol. 4 : Iss. 2 , Article 5.

Available at: https://doi.org/10.53728/2765-6500.1087

This Article is brought to you for free and open access by Asia Marketing Journal. It has been accepted for inclusion in Asia Marketing Journal by an authorized editor of Asia Marketing Journal. 


\title{
인지-감성소구의 광고평가에 대한 사전지식과 관여도의 상대적 역할*
}

\section{The Relative Role of Prior Knowledge and Involvement on Cognitive-Affective Advertising Evaluation}

\author{
황윤용(전북대학교 경영학부 강사) \\ yyhwangebusiness. chonbuk.ac. $\mathrm{kr}$ \\ 나광진(전북대학교 경영학부 강사) \\ jinny5322 chanmail.net
}

본 연구는 소비자들의 광고평가과정을 정보처리능력의 관점인 사전지식과 정보처리동기의 관점인 관여도의 조절적 역할울 고려하여 검토하였다. 이를 위하여 본 연구에서는 인지자극과 감정자극이 동시에 제공된 광고에 대하여 소비자들의 인지적, 감정적, 행동의욕적 평가관계를 구조적으로 살펴보고, 이를 바탕으로 각 구조적 관계들을 사전지식수준과 관여도수준에 따라 그 상대적 역할들을 살펴보았다. 실증분석결과 본 연구는 기존의 $\mathrm{DMH}$ 모델을 지지하는 것으로 나타났으며, 특히 광고에 대한 감정적 평가(Aad)에서 상표에 대한 인지적 평가 $(\mathrm{Cb})$ 통해 상표에 대한 감정적 평가 $(\mathrm{Ab})$ 에 미치는 영향력의 정도는 관여도보다는 사전지식이 더 큰 역할을 하는 것으로 나타났다. 또한 광고에 대한 감정적 평가(Aad)에서 상표에 대한 감정적 평가(Ab) 그리고 상표에 대한 감정적 평가 $(\mathrm{Ab})$ 에서 상표에 대한 행동의욕적 평가 $(\mathrm{Ib})$ 로의 영향력은 관여도가 중요 조절변수임을 확인하였다.

* 논문접수: 02.10 게재확정: 02.11

본 논문에 유익한 조언을 주신 익명의 심사위원닙틀깨 감사드립니다. 


\section{1. 서론}

광고에 대한 태도(attitude toward advertisement)란 특정 노출상황에서 톡정 광고자극에 대하여 광고수용자가 호의적 또는 비호의적으로 반응하는 선유경향(predisposition)을 말한다(MacKenzie, Lutz and Belch 1986). 그 동안 광고효과나 광고메시지의 정보처리 메커니즘에 대하여 주로 인지적 반옹을 중심으로 많은 연구가 수행되어 왔으나 근래에는 감정적 측면을 고려한 연구들도 활발하게 이루어지고 있다(김완석 1993; 이학식 1991; Batta and Ray 1986; Burke and Edell 1989; Hill and Mazis 1986). 이들은 Fishbein and Ajzen(1975)의 합리적 행동이론(theory of reasoned action), Greenward(1968)의 인지반웅(cognitive response) 이론과 같이 기존의 정보처리론적 광고효과이론들이 주로 언어적 메시지에 대한 인지적 반웅올 중시하고, 소비자의 감정적 촉면을 소홀히 다루고 있음을 지적하며, 소비자들이 기존의 심리학적 또는 정보처리적 관점의 주요한 가정이었던 합리적인 의사졀정보다는 감정적 측면과 관련된 의사결정이 크게 이루어지고 있음을 주장하였다. 이러한 현상을 반영하듯, 최근의 광고들은 상품자체의 정보를 제공하는 광고에서 각종 시청각요소를 통해 분위기와 이미지률 강조하는 감정적 측면의 소구내용을 많이 다루고 있다. 또한 광고의 기능도 전통적인 정보기능 외에도 단순하면서도 간접적인 이미지 창출 또는 오락기능 등이 매우 중요하게 부각되고 있다(김완석 1995).

한편, 많은 연구자들이 소비자의 정보처리과정과 관련하여 주의(attention), 이해(comprehension), 설득(persuasion)과정에 대한 능력 및 동기적 선행요인들에 관심을 가져왔다. 능력변수로서 폭넓게 검토되어 온 변수로는 사전지식(prior knowledge), 전문성(expertise), 친숙성(familiarity) 그리고 이용빈도(frequency of use) 등이 처리된 정보의 양(Brucks 1985; Johnson and Russo 1984), 단서이용(Rao and Monroe 1988), 평가과정 (Sujan 1985), 회상 (Zinkhan and Muderr i soglu 1985), 정교화과정 (Brucks 1985; Celsi and Olson 1988; Sujan 1985)에 영향을 미치는 것으로 알려져 왔다. 그리고 동기변수로서 주로 검토되어 온 변수는 관여도인데 이는 설득경로(Chaiken 1980; Krugman 1965, 1977; Petty and Cacioppo 1979), 주의와 이해(Celsi and 0lson 1988; Petty et al., 1983), 정교화과정(Celsi and 01 son 1988; Kardes 1988; Pet ty and Cacioppo 1981; Richins and Block 1986)에 영향을 미치는 것으로 알려겨 왔다. 그러나 이와 같은 정보처리과정에 대한 능력과 동기변수들의 영향력올 검토한 많은 연구들이 있기는 하나 대부분이 개별적 관점에서 접근되었고 능력과 동기의 상대적 효과를 검토한 연구들은 매우 미홉한 편이다. 톡히 기존에 주로 다루어 왔던 인지적 측면의 소구내용뿐만 아니라 감정적 측면에서의 소구내용이 동시에 소비자에게 노출되었을 때 사전지식과 관여도의 상대적 역할에 대한 연구는 매우 미미한 실정이다. 따라서 본 연구는 최근 많이 나타나고 있는 지역소구광고(local appeals advertising)의 정보처리과정을 중심으로 접근성 (accessibility)과 진단성(diagnosticity)의 개념을 도입하여 사전지식과 관여도의 상대적 효과를 검토해 보고자 한다. 특히, 본 연구에서는 소비자의 정보처리과정을 중심으로 광고평가와 상표평가의 관계 그리고 상표평가와 행동의욕적 평가의 관계를 사전지식과 관여도의 관점에서 검토하고자 한다. 


\section{2. 이론적 배경}

\section{1 광고소구}

광고소구(advertising appeal)란 소비자들의 주의와 관심을 유발하거나 또는 제품, 서비스에 대한 소비자의 느낌에 영향을 주기 위해 사용되는 방법을 말하는데, 크게 이성적 소구(rational appeal)와 감정적 소구(affective appeal)로 나눌 수 있다.

\section{1 .1 이성적 소구}

이성적 소구는 흔히 정보 제공적 소구(informational appeal)라고도 하는데 이는 소비자가 광고를 본 후에 제품구매의 장점올 평가할 수 있도록 하기 위하여 관련된 사실적 정보들을 명료하고 논리적인 방법으로 제시하는 형태를 말한다. 이러한 형태를 통하여 제품에 대한 정보를 얻음으로써 이성적인 소비자는 제품의 특성을 구별하여 구매의사결정올 내리게 된다. 그러나 때때로 소비자들이 이성적이지 못하고 정보를 구하려는 관심이 부족함에도 불구하고 소비자에게 왜 그 제품을 구매해야 하는가에 대한 이유를 논리적이고 사실적으로 제시하는 형태로써도 소비자에게 충분히 직접적이고 정보지향적인 영향력을 심어줄 수 있다.

이처럼 이성적으로 소구하는 광고는 소비자의 실용적, 기능적, 효용적 욕구에 초점을 맞추고 있다. 따라서 이성적으로 소구하는 광고는 제품이 가지고 있는 특정 속성이나 편익을 강조하여 소비자의 구매를 적극적으로 유도하고자 한다. 또한 기업입장에서는 정보제공적 측면에서 자사 제품 또는 서비스가 소비자들의 역구를 충족시켜 줄 수 있는 특별한 효익을 가지고 있음을 확신시켜 주기도 한다.

\section{1 .2 감정적 소구}

오늘날 많은 광고는 감정적 소구를 이용하여 소비자들의 본능적 욕구를 환기시키려 하고 있다. 감정적 소구를 하는 광고에서는 로맨스, 향수, 동정, 훙분, 기뽐, 두려움, 죄의식, 슬픔 등 자기자신과 관련된 개인적 감정과 존경, 자아이미지 고취, 지위, 과시 등 타인들과의 관계에서 비롯되는 심리상태인 사회지향적 감정 등의 온갖 긍정적 또는 부정적인 감정들을 이용하여 소구한다.

이처럼 감정적 소구는 제품구매의 심리적 욕구 또는 사희적 욕구에 초점올 맞추고 주로 긍정적 정서를 조성하려고 한다. 또한 감정적 소구는 소비자의 기억반웅에 긍정적인 장기적 효과가 있으며 호의적인 판단반웅올 일으킨다. 특히 Friestad and Thorson(1986)에 따르면 감정적 소구를 소비자가 경험할 수 있는 정감의 양을 조절하는 수단이라고 하였다. 이러한 접근법에 의하면, 정서적으로 환기되어 있는 동안에 경험한 일화적(espiśodic) 사건은 그렇지 않은 경우보다 강한 기억흔적을 남기며, 이 기억흔적은 제품과 관련된 의미적(semantic) 기억흔적에 통합될 수 있으며, 이러한 효과는 고관여 상황하에서 발생할 가능성이 크다고 보았다.

한편 Golden and Johnson(1983)의 연구에서 4가지 제품범주의 TV광고를 활용하여 감정, 정보의 양, 정보의 유용성, 정보의 신빙성, 구매의도를 측정하여 본 결과 감정과 정보의 양, 
유용성, 신빙성에 대한 감각적 선호와 광고소구의 효과는 유의하지 않았지만, 이성적 광고물은 감정직 광고물보다 더 선호되었으며 보다 유용한 정보를 더 내포한 것으로 지각되어 더 긍정적인 구매의도를 유발하는 것으로 나타났다.

\section{2 사전지식과 관여도}

\section{2 .1 사전지식}

소비자들의 문제해결과정은 그들의 과거 경험이나 제품에 대한 관여수준 또는 제품의 선택과정을 통하여 얻어진 제품에 대한 지식의 양에 의하여 매우 크게 영향올 받는다. 소비자가 추구하는 목표(goals) 또는 그 목표를 위한 선택대안(choice alternatives)과 선택기준(choice criteria)에 관하여 활성화된 지식은 효과적인 의사졀정울 위한 소비자의 능력에 영향을 미친다. 일반적으로 해당된 문제해결의 유형에 따라 지식의 역할을 살펴보면 목표에 대한 위계(goal hierarchy)에 있어서 낮은 지식을 가진 집단은 단순한 위계로서 목표가 불명확하거나 잘 정의되어 있지 않으며 목표에 관하여 불확실성이 내재해 있다. 반면에 지식이 높은 집단은 명확하고 잘 정의된 하위목표를 가지고 있으며 복잡한 하위체계로서 구성되어 있다. 또한 고려범주(consideration set)와 선택기준에 대하여 지식이 낮은 집단은 소수의 선택대안들이 알려지거나 고려되어 소수의 고정된 속성들을 선택기준으로 이용하기도 하고, 아울러 제품에 대한 중요한 정보기준들에 관해서도 명확하계 알지 못하고 있다. 그러나 지식이 높은 집단은 다수의 선택대안들을 고려하고, 선택기준으로서 제품과 관련된 구체적 속성정보나 또는 외부적 단서와 같은 관련 있는 폭넓은 범주의 제품지식을 이용할 수 있다. 따라서 소비자들이 관련된 정보를 처리하는 과정에서 사전지식이 높을수록 제품에 대한 인지적 평가를 보다 더 정확하게 할 수 있다.

한편, 많은 연구자들은 이러한 사전지식(prior knowledge)올 소비자가 제품과 관련하여 알고있다고 생각하는 정도인 주관적 지식(subject knowledge)과 제품에 관해서 실제로 알고있는 정도인 객관적 지식(object knowledge)의 조합된 개념으로 다루어 왔다(Park and Lessig 1981; Rao and Monroe 1988). 또한 Marks and 0lson(1981)은 이와 같은 사전지식을 기존의 제품경험에 대한 인지적 표상으로 정의하였다. 이러한 표상들은 제품과 관련된 인지적 구조(cognitive structure) 또는 스키마(schema)로서 기억속에 부호화되고 조직화 된 것을 의미한다. 그리고 인지적 구조는 공식적이거나 비공식적인 학습과정과 제품경헙, 구전, 대중매체 둥을 통하여 획득된 객관적 지식과 주관적 지식의 제 요소들을 포함하고 있다. 톡히, 반복 노출이나 제품정보의 부호화는 더 세밀하고 신뢰할 만한 인지구조률 야기시켜 주고 있다. 따라서 더 잘 개발된 인지구조는 제품에 관한 더 많은 지식을 가지고 있음을 의미한다(Zinkhan and Muderrisoglu 1985). 그러므로 만약 어뗜 소비자가 제품에 관해 잘 발달된 지식구조를 가지고 있다면 그 소비자는 제품의 속성들과 기억속에 이미 존재하고 있는 단서들간의 연상을 더 쉽게 할 수 있다. 이것은 기억시연올 야기하고 더 나아가 메시지주장에 대한 평가를 더 잘 할 수 있게 한다. 반면에, 제품에 관해 빈약한 지식을 가지고 있는 소비자는 덜 발달된 기억구조를 가지고 있고, 따라서 이러한 소비자들은 제품속성과 관련된 기존단서들의 인출이 매우 미약하며, 이에 따라 기억시연과 메시지주장에 대한 평가가 매우 약하게 수행된다. 


\section{2 .2 관여도}

관여도(involvement)란 특정 대상에 대한 개인의 중요성 지각정도 및 관심의 정도이거나 또는 주어진 상황에서 특정 대상에 대한 개인의 관련성 지각정도라고 정의할 수 있다. 이와 같은 관여도에 대하여 정교화가능성모델(elaboration likelihood model: ELM)은 설득적 메시지에 대하여 고관여 소비자는 정교화가능성이 높아 주로 중심경로에 의한 정보처리가 이루어지며, 반대로 저관여 소비자는 정교화가능성이 낮아 주로 주변경로를 활용하여 정보처리를 한다고 제시하고 있다(Petty, Cacioppo and Schumann 1983). 따라서 소비자가 특정광고에 노출되었을 때 광고된 제품군에 보다 더 관여된 소비자의 경우는 기존에 있던 자신의 태도률 유지하는 방향으로 상표를 평가하려 할 것이며, 이에 비해 보다 덜 관여된 소비자의 특정 광고에 대한 태도는 일시적인 현상을 보이려 할 것이다. 이처럼 소비자가 특정 광고제품에 대하여 고관여 상태이면 그 제품과 관련된 정보룰 추적하는데 적극적이고 능동적인 정보처리를 하므로 보다 인지적이고 의식적으로 정보처리가 이루어지는 강화된 전략적 정보처리(strategic information processing)를 하게 된다. 그러나, 소비자가 저관여 상태이면 소극적이고 수동적인 정보처리가 이루어져 고관여 상태와 같은 구체적 인지에 의해서 평가하기는 어렵고 주로 주변경로에 따라 평가가 이루어질 것으로 기대할 수 있다. 따라서 이때에는 주어진 특정 상황과 결부시키거나 단순한 추측 등에 의해서 무의식적인 정보처리가 주로 이루어지는 자동적 정보처리(automatic information processing)가 이루어지게 되며, 상대적으로 인지적 노력을 필요로 하는 전략적 정보처리의 정도는 미약할 것으로 기대할 수 있다.

한편, 대다수의 연구자들은 관여도의 근본적인 특색을 지각된 개인적 관련성(perceived personal relevance)으로 보고 있다(Celsi and 01son 1988; Richins and Block 1986; Zaichkowsky 1985a). 이들은 특정 제품에 대한 개인적 관련성울 개인의 욕구, 목표, 가치 등과 개인이 가지고 있는 제품에 관한 지식사이의 지각된 결합(linkage)이라고 설명하며, 따라서 개인적 관련성에 대한 한 개인의 느낌은 자극과 관련된 정보를 획득하고 처리하는데 필요한 정보탐색동기라고 보았다. Celsi and $01 \operatorname{son}(1988)$ 은 이러한 동기적 상태를 주관적 관여도(felt involvement)라 하였다. 어떤 소비자가 광고메시지에 노출되었을 때 만약 그 소비자가 자극과 관련된 주관적 관여도가 낮은 상황하에 있다면 별다른 인지적 노력을 기울이지 않고 주어진 메시지률 피상적으로 처리하게 될 것이다. 반면 주관적 관여도가 높은 소비자는 메시지의 이해나 정교화 및 평가에 있어서 매우 높은 인지적 노력을 기울이게 될 것이다(Greenwald and Leavitt 1984; Zinkhan and Muderrisoglu 1985).

한편, Celsi and 0lson(1988)은 이러한 주관적 관여도의 원천이 개인의 장기기억속에 저장되어 있거나 과거 경험으로보터 획득되어서 특정 대상에 대한 개인적인 관련지식이 쉅게 변화하지 않는 지속적 관여도(enduring or intrinsic involvement)와 소비자가 직면한 자극, 단서 등의 특정 상황에서 형성되어 일시적인 성격을 가지고 있는 상황적 관여도(situational involvement)로 구분하고 있다. 즉, 지속적 관여도는 개인적 관점에서 제품에 대한 개인의 지속적 관련성을 의미하며, 반면에 상황적 관여도는 일시적인 환경적 단서들에 의해서 나타나는 것을 의미한다. 그러나 이 둘은 결국 주관적 관여도(felt involvement)를 형성하는 요소들이다(Celsi and Olson 1988; Houston and Rothschild 1978).

따라서 개인의 인지적 상태의 관점에서 살펴본다면 사전지식은 하나의 자극에 대하여 인지적 구조가 얼마나 잘 발달되어 있는가를 의미하며(능력상태), 반면 관여도는 하나의 자극이 주어진 상황하에서 얼마나 잘 활성화되어지는가의 정도를 말한다(동기상태). 


\subsection{3 사전지식과 관여도의 관련성}

앞에서도 살펴보았듯이 결국 사전지식(처리능력)과 관여도(처리동기)는 모두 소비자의 정보처리과정에 영향을 준다고 볼 수 있다. 톡히 사전지식과 지속적 관여도는 모두 소비자의 장기기억속에 저장된 정보를 고려하기 때문에 양자는 메우 밀접한 관련성이 있다고 볼 수 있다. 물론 이 두 개념간의 관련성 정도는 제품범주에 따라 변화할 수 있다. 왜냐하면 어떤 소비자는 제품에 대한 지속적 관여가 없이도 그 제품과 매우 높은 친숙성올 가지고 있거나 높은 지식수준을 가지고 있을 수 있기 때문이다. 그러나 일반적으로 여러 선행연구들의 결과들을 종합해 보면 지식수준과 관여도가 매우 밀접한 관계가 있음을 시사하고 있다(Celsi and Olson 1988; Zinkhan and Muderrisoglu 1985). 지속적 관여와 사전지식의 관계가 더 강하면 강할수록 정보처리적 측면(즉, 주의, 이해, 정교화, 회상, 평가)에서 이들의 효과를 분리하는 것은 더 어려워진다. 즉, 하나의 효과가 다른 것에 의해서 더 명확하게 된다든지 또는 희석될 수 있기 매문이다. 반면, 이 둘 간의 관계가 약하면 약할수록 이들이 상호 독립적이거나 또는 분리효과를 가지기가 더 쉽다.

그러나 서두에서도 언급했돗이 정보처리적 관점에서 지속적 관여도와 사전지식의 상대적 효과를 살펴본 연구는 매우 드물다. Celsi and 0lson(1988)의 테니스 제품을 대상으로 한 연구에 의하면 제품에 대한 지식과 지속적 관여도의 상관관계가 $\mathrm{r}=0.61$ 로서 매우 높은 관련성이 있음울 확인하였다. 그들은 또한 지속적 관여보다는 제품지식이 주의와 정교화의 집중도에 유의적인 효과가 있음을 발견하였다. 반면에 지속적 관여도는 지식과 달리 주의의 양에 유의적인 효과가 있었다. 그리고 상황적 관여도는 모든 경우에 있어서 유의적인 요인으로 작용하였다. Zinkhan and Muderrisoglu(1985)는 자동차와 스테레오장비를 이용한 연구에서 관여도와 지식의 상관관계가 $\mathrm{r}=0.25$ 로서 상대적으로 매우 낮은 관련성이 있다고 보았다. 이들의 연구에 의하면 지식과 관여도는 광고회상에 대하여 분리된 효과(즉, 개별효과)를 보여주었다. 반면에 Sujan(1985)은 카메라제품범주를 대상으로 관여도와 지식의 관계를 살펴보았는데 이 연구에 의하면 둘간의 상관관계가 $\mathrm{r}=0.51$ 로 나타났다. 한편, Celsi and 01son(1988)의 연구는 지속적 관여와 지식이 매우 높게 상관되어 있을 때 양자간의 독립적인 효과들은 없옴올 보여주었다. 반면 Zinkhan and Muderrisoglu(1985)의 연구는 지식과 관여도가 낮게 상관되었을 때 양자가 독립효과가 있음을 확인하였다. 그런데, 사전지식과 관여도의 관계가 높거나 닞은 이유는 무엇일까?

기존의 관련 연구들을 토대로 사전지식과 관여도의 관계를 종합해 보면 다음과 같다. 먼저 소비자에게 주어진 자극이 기억속에서 실제로 작용할 가능성은 장기기억으로의 접근성(accessibility)과 자극의 진단성(diagnosticity)에 의해 결정된다고 볼 수 있다(Ahluwalia and Gurhan-Canli 2000). 즉, 소비자가 머럿속에 있는 정보를 기준으로 제품올 평가한다고 가정했을 때 어떠한 정보가 기억으로부터 인출되고 평가에 활용되는가의 여부는 마케터에게 매우 중요한 의미를 주고 있다. 왜냐하면 마케터는 자사의 제품이나 서비스에 대해서 소비자들의 기억을 중심으로 평가한다고 했을 때 이들이 이용하는 정보를 광고나 기타 판촉활동 등을 통하여 강조할 수 있기 때문이다. 따라서 이와 같은 중요성에 입각하여 Feldmen and Lynch(1988)는 이를 설명할 수 있는 이론으로서 접근성과 진단성 모델(accessibility-diagnosticity model)을 제시하였는데, 이 모델에 따르면 소비자들은 자신들의 머릿속에 있는 정보들 중 접근이 용이하고 진단가능한 정보들올 골라 이용한다고 한다. 이때 정보의 접근성은 그 정보가 과연 얼마나 자주 그리고 최근에 소비자의 머릿속에 자리잡게 되었는가와 소비자가 과연 얼마나 심각하게 고려했는가에 의해서 결정되는 것이고, 
정보의 진단성은 소비자가 얼마나 제품속성들의 특성돌에 대하여 잘 알고 있는가에 의하여 결정된다고 보았다. 따라서 만약 소비자가 주어진 정보에 대하여 접근성과 진단성이 높다면 이를 토대로 기억에 근거한 판단과 선택(memory-based judgement or decision)을 용이하게 할 수 있다(Lynch et al., 1988). 그리고 이때 소비자의 특정 자극에 대한 접근성과 진단성을 강화시켜줄 수 있는 수단이 바로 소비자가 이미 가지고 있는 사전지석(prior knowledge)이라 할 수 있다.

한편, 소비자들이 소비하는 제품들은 물리적인 측면에서 본다면 속성의 덩어리(bundle of attributes)라 할 수 있다. 그러나 소비자들이 특정 제품을 구매하는 이유는 제품의 물리적 속성들 그 자체보다 그러한 속성들에 의해서 실현되는 제품효익(product benefit) 때문이다. 따라서 제품을 소비자중심적 사고에서 보면 효익둘의 묶음(bundle of benefits)으로 불 수 있다. 그리고 소비자들은 이 효익의 묶음들을 통해서 자신들이 추구하는 가치를 얻으려고 하는데, 이를 설명하는 이론이 수단-목표 사슬(means-ends chains)이다(Jonathan 1982). 수단-목표 사슬은 제품속성들과 이 속성들에 의해 형성되는 결과들을 함께 연결시키는 지식구조라 할 수 있다. 즉, 소비자들의 제품에 대한 지식(속성과 그 속성이 가지고 있는 효익)과 자아지식(중요한 심리적, 사회적 결과와 가치)과의 연결에 대한 인지적 표현이라 할 수 있는데, 이의 연결정도가 소비자의 특정 제품에 대한 관여의 정도률 설명할 수 있다고 보고 있다. 따라서 수단-목표 사슬과 관여도의 관계를 고려해 본다면 소비자가 왜 특정 제품과 그 제품에 대한 정보탐색에 대하여 더 많은 관여률 하고, 더 많은 구매 및 사용을 하는가률 설명할 수 있다. 결과적으로 특정 제품에 대하여 소비자들이 저관여상태에 있다라는 것은 제품이 가지고 있는 물리적 속성과 소비자가 추구하는 가치의 연결강도가 낮다는 것을 의미하며 이는 곧 그 졔품과 관련된 수단-목표지식구조가 낮개 형성되어 있음을 시사해 주고 있다. 반면에 고관여소비자의 경우에는 수단-목표지식구조가 상대적으로 길고 복잡한 구조를 가지고 있고 이에 따라 제품의 특정 속성이 소비자 자신의 활동과 자아가치표현에 어떻게 도움을 주는지를 보다 더 잘 알고 있다고 할 수 있다(Celsi and 01 son 1988). 따라서 소비자의 정보처리과정에 정보처리동기와 정보처리능력의 요소로서 고려되는 관여도와 사전지식은 매우 밀접한 관련성이 있다고 할 수 있다.

\section{3 사전지식, 관여도와 상표평가}

인지와 감정은 서로 다른 심리적 반웅이다. 인지는 인간의 의식적인 정신적 반웅으로서 지식의 습득 및 저장과 관련한 반응들이며, 신체반웅을 거의 돟반하지 않는다. 반면에 감정은 느낌이나 분위기에 관한 경험이며 대개 신체반응을 동반한다. 예를 들어, 소비자들은 특정 대상에 대하여 " 그 광고는 내용이 너무 산만하다" , "그랜저는 비싸다" 등과 같은 반응들은 인지적 반응이라 할 수 있고, "그 광고는 나에게 행복감을 준다" , “TV의 월드컵 응원 광고를 보면 가슴이 뭉클하다" 와 같은 것은 감정적 반옹이라 할 수 있다.

소비자를 이해하기 위해서는 인지와 감정 모두룰 이해하는 것이 매우 중요하다. 왜냐하면 인지와 감정은 각각 인지체계와 감정체계에 의한 반옴일지라도 이 두 체계는 매우 밀접한 상호관련성을 가지고 있기 때문이다. 예를 들어 사랍들은 놀랐을 때 자기가 알고 있던 것도 생각이 잘 안나며, 반면 기분이 좋을 때에는 즐거웠던 일이 더 많이 생각나게 된다.

인지와 감정에 대한 이와 같은 견해를 바탕으로 소비자의 태도(attitude)를 설명할 때 
크게 두 가지 견해로 나누어 살펴볼 수 있다. 하나는 인지와 감정을 태도를 형성하는 각각의 구성체로 보는 관점이다. 이 관점에서는 태도률 인지적 요소(cognitive component), 감정적 요소(affective component), 행동의욕적 요소(conative component)에 의해서 구성된다고 보는데, 소비자가 어떤 대상이 긍정적인 효익(benefits)을 가져다 준다고 믿으면, 그 대상을 좋아할 가능성이 높고, 이에 따라 그것을 구매할 가능성이 크다고 보고 있다.

한편, 태도에 대한 또 다른 견해는 전술한 세 가지 차원중 오직 감정적 요소만이 태도로 간주되며 인지적 요소와 행동의욕적 요소는 각각 신념(beliefs)과 행동의도(behavioral intentions)로 개념화되어, 태도는 감정적 요소만으로 구성되는 단일차원으로 간주되고 인지적 요소와 행동의욕적 요소는 태도의 구성요소가 아니라 각각 태도의 선행요인과 결과요인으로 보고 있다. 오늘날 태도의 3 요소 견해와 단일차원 견해 중 후자가 더 지지되고 있다. 따라서 본 연구도 이러한 관점에서 소비자가 특정 제품의 광고에 노출되었을 때 먼저 인지적 반웅 $(\mathrm{Cb})$ 이 이루어지고 이러한 인지적 반웅울 통하여 감정적 평가 $(\mathrm{Ab})$ 와 행동의욕적 평가(Ib)가 이루어질 것으로 예상한다.

$\mathrm{H} 1$ : 상표에 대한 인지적 평가 $(\mathrm{Cb})$ 는 상표에 대한 감정적 평가(Ab)에 유의적인 영향을 미칠 것이다.

$\mathrm{H} 2$ : 상표에 대한 감정적 평가 $(\mathrm{Ab})$ 는 상표에 대한 행동의욕적 평가( $\mathrm{Ib}$ )에 유의적인 영향을 미칠 것이다.

\subsection{1 인지적 평가와 감정적 평가}

인지적 반웅(cognitive response)은 소비자가 정보처리를 하는 동안 자연스럽게 갖는 생각으로서 이를 광고와 관련지으면 광고메시지에 대한 인지적 반응, 광고실행에 대한 인지적 반웅, 혹은 광고와 무관한 인지적 반응 등으로 살펴볼 수 있다. 특히 광고메시지에 관한 인지적 반응과 광고실행에 대한 인지적 반응은 긍정적일 수도 있고 부정적일 수도 있는데 그 유형을 보면 다음과 같다. 먼저 광고메시지에 대한 것으로 지지주장(support arguments)과 반박주장(counter arguments)이 있다. 먼저 지지주장은 소비자의 기존 신념체계에 비추어 유입정보가 대체로 일치한다고 소비자가 느낄 때 일어나는 반웅이며, 반박주장은 유입된 정보가 소비자의 신념체계에 배치될 때 일어나는 반응을 말한다. 또한 광고실행에 대한 반응으로 실행지지(execution bolstering)와 실행격하(execution derogation)가 있는데, 실행지지는 광고실행에 대한 긍정적 반옹울 의미하며, 실행격하는 광고실행에 대한 부정적 반응을 의미한다.

한편, 광고에 대한 소비자의 인지적 반웅은 상표태도에도 영향을 미치는데 지지주장과 실행지지는 긍정적으로, 반박주장과 실행격하는 부정적인 영향을 미친다. 즉, 제품광고에 노출된 소비자가 지지주장과 실행지지를 더 많이 떠올리게 되면 소비자는 긍정적인 상표태도를 형성하게 되지만, 반대로 소비자가 반박주장이나 실행격하를 많이 하게 되면 소비자는 부정적인 상표태도를 형성하게 된다. 또한 지지주장과 반박주장 같은 메시지와 관련된 인지적 반옹은 소비자가 고관여 상태일 때 많이 일어나는 경향이 있으며, 실행지지나 실행격하 같은 광고실행에 관한 반응은 저관여 상태일 때 비교적 많이 발생하는 것으로 밝혀지고 있다(Petty and Cacioppo 1983). 또한 인지적 반응은 소비자가 이미 가지고 있는 사전지식 즉, 인지적 구조의 매개작용을 통하여 상표에 대한 태도에 영항을 미친다. 
소비자의 인지적 반웅은 소비자가 상표 또는 제품에 대하여 가지고 있는 속성별 신념과 신념에 대한 평가에 의해 나타나는데 이의 대표적인 모델이 Fishbein 도델이라 할 수 있다. 따라서 광고제품에 대한 소비자의 인지적 평가가 상표에 대한 태도 즉, 상표에 대한 감정적 평가에 미치는 영향력은 정보처리 동기률 활성화시켜주는 관여도가 높을수록, 그리고 정보처리 능력을 강화시켜주는 사전지식수준이 높을수록 더 클 것으로 예상할 수 았다.

$\mathrm{H} 3 \mathrm{a}$ : 상표에 대한 인지적 평가 $(\mathrm{Cb})$ 가 상표에 대한 감정적 평가 $(\mathrm{Ab})$ 에 미치는 영향력은 관여도가 낮은 집단보다 높은 집단에서 더 클 것이다

$\mathrm{H} 3 \mathrm{~b}$ : 상표에 대한 인지적 평가 $(\mathrm{Cb})$ 가 상표에 대한 감정적 평가 $(\mathrm{Ab})$ 에 미치는 영향력은 사전지식이 낮은 집단보다 높은 집단에서 더 클 것이다

Petty and Cacioppo(1981)의 정교화가능성 모델(elaboration likelihood model)에 의하면 소비자의 태도형성과정은 소비자가 정보를 처리하는 노력의 정도에 따라 다르다고 보고 있다. 즉, 소비자가 주어진 정보를 처리하는데 상당한 노력을 기울일 경우 이때의 태도형성은 중심경로(central route)를 통해서 이루어지고, 반면에 정보처리를 위해 그다지 노력을 기울이지 않을 경우 주변경로(peripheral route)를 통해 이루어진다. 그런데 이 때 소비자가 제품정보률 처리하려는 노력의 정도(elaboration likelihood)는 소비자가 제품정보롤 처리하려는 동기(motivation)와 능력(ability)에 의해 결정된다. 제품정보가 자신과 직접관련성(personal relevance)이 높은 경우, 7 제품을 처리하려는 동기가 높아지며, 또한 소비자가 제품에 대한 사전지식이 많고, 제품정보에 대한 이해력이 높을수록, 제품정보를 처리할 수 있는 능력이 커지게 되므로 정보처리노력의 정도가 높아지게 된다. 그러나 만약 소비자가 광고에서 주어진 커뮤니케이션 정보를 처리할 동기부여가 있더라도 실제로 그 정보와 관련된 인지구조가 명확하지 못하여 정보에 대한 진단적(diagnostic) 판단능력이 미약할수록 인지적 반옹에 의한 정보처리보다는 주변단서를 통해서 커뮤니케이션 정보를 처리하기가 쉽다. 왜냐하면 정보의 판단이나 선택행동에 영향을 미친다는 접근성-진단성 모델에 따르면 지각된 진단성(perceived diagnosticity)이 낮다는 의미는 제시된 정보의 사용가능성을 저해하기 때문에 소비자에게 인지적인 처리능력을 요구하는 특정 정보의 처리 가능성을 감소시킨다고 볼 수 있기 때문이다(Herr, Kardes and Kim 1991), 반대로 지식수준이 높은 소비자들은 정보에 대한 진단을 보다 잘 할 수 있기 때문에, 속성에 대한 평가와 신념구조에 의해 형성되는 상표태도에도 보다 더 강한 영향을 미친다고 예상 할 수 있다.

따라서 소비자의 인지적 평가에 의한 태도의 형성은 동기부여를 활성화 시켜주는 관여도의 수준보다는 인지적인 정보처리 능력을 의미하는 사전지식이 더 큰 영향올 미치리라 예상할 수 있다. 이는 소비자의 광고제품에 대한 인지적 평가가 그 제품의 감정적 평가에 미치는 영향력이 관여도 수준보다는 사전지식수준에 의해 더 크게 조절됨을 의미한다.

$\mathrm{H} 3 \mathrm{c}$ : 상표에 대한 인지적 평가 $(\mathrm{Cb})$ 가 상표에 대한 감정적 평가 $(\mathrm{Ab})$ 에 미치는 상대적 영향력은 관여도가 높은 집단보다 사전지식이 높은 집단에서 더 클 것이다. 


\section{3 .2 광고평가와 상표평가}

광고에 대한 태도(attitude toward advertisement: Aad)와 관련하여 MacKenzie, Lutz and $\mathrm{Belch}$ (1986)는 기존의 광고에 대한 태도의 여러 인과관계 모댈들[즉, 감정전이모델(affect transfer model), 이중매개모델(dual mediat ion model), 상호매개모델(reciprocal mediation model), 독립영향모델(independent influences model)] 을 토대로 어떠한 모델이 광고에 대한 태도의 역할을 가장 잘 설명하고 있는가를 검토하였다. 그 졀과 광고에 대한 태도가 상표에 대한 태도(attitude toward brand: $\mathrm{Ab}$ )에 직접적 영향을 미치며 또한 간접적으로 상표에 대한 인지(cognition of brand: $\mathrm{Cb}$ )에도 영향을 미치는 이중매개모델이 가장 나은 설명력이 있는 것으로 조사되었다. 특히, 그들의 결과에 의하면 저관여상태의 소비자일 경우 Aad에서 $\mathrm{Ab}$ 로 강한 정 $(t)$ 의 관계가 있음을 알 수 있었고, 또한 $\mathrm{Aad}$ 에서 $\mathrm{Cb}$ 로도 유의적인 정 $(t)$ 의 영향력이 있는 것으로 나타났다. 그들은 이러한 결과에 대한 이유를 광고자극에 대한 소비자의 감정적 반웅이 광고상표의 주장을 수용하는 데 영향을 미치며 결국 이는 $\mathrm{Ab}$ 에 영향을 미치기 때문이라고 보았다. 따라서 소비자가 광고에 대해 우호적인 감정을 많이 느낄수록 광고에서 주장하는 내용을 더 많이 수용한다고 보았다.

또한 이러한 현상은 소비자의 지식수준에 의해서도 영향을 받기가 쉬운데, 노출된 광고정보에 대하여 소비자가 잘 활성화된 제품지식을 가지고 있다면 좀더 정교화 과정을 거칠 수 있으므로 상표에 대한 인지적 평가를 보다 잘 수행할 수 있고 이를 통해 상표태도가 형성될 것으로 기대할 수 있다. 그러나 만약 소비자가 빈약한 사전지식을 가지고 있다면 광고에서 제시된 상표관련 스키마를 활성화시키지 못할 것이며 따라서 상표에 관해서 정교화 과정올 잘 수행하지 못할 것이다. 또한 만약 정교화 과정을 수행한다 하더라도 비교적 얕고 제한된 수준의 상표관련 정보처리를 할 것이며 광고메시지와 관련된 인지적 반응을 거의 보이지 않을 것이다. 따라서 이러한 상황에서는 잘 체계화된 상표와 관련된 인지적 평가를 토대로 상표에 대한 감정적 평가가 이루어지기보다는 광고에 대한 감정적 평가가 그대로 상표에 대한 감정적 평가로 전이되기가 더 쉽다.

한편, 노출된 광고를 통해 소비자가 자연스럽게 가지는 광고에 대한 감정적 평가가 상표에 대한 감정적 평가에 영향을 미치는 정도는 소비자가 가지고 있는 인지적 스카마에 의한 영향보다는 일시적인 태도률 형성하게 하는 주변단서률 통한 영향력이 더 크다고 볼 수 있다. 따라서 이 때에는 정보처리능력보다는 정보처리동기에 의해서 영향을 받기가 쉽다. Grunert(1996)은 인지적 관점에서 이러한 점올 정보원천의 처리가 특별한 의식적 노력이 필요 없이 병렬적 형태의 자동적인 과정으로 나타난다고 제시하였는데 이것이 곧 정보의 자동적 처리과정(automatic information processing)이다. 그러므로 노출된 광고의 감정적 평가가 상표에 대한 감정적 평가에 직접적인 영향을 미치는 정도는 정보처리의 능력보다는 정보처리의 동기수준에 의해서 영향을 받기가 쉬우며, 이때 정보처리 동기가 낮을 경우(즉, 관여도가 낮은 상황) 주변단서률 활용하여 더 빠른 감정전이 현상이 발생할 수 있다. 
$\mathrm{H} 4$ : 광고에 대한 감정적 평가(Aad)는 상표에 대한 감정적 평가(Ab)에 유의적인 영향을 미칠 것이다.

$\mathrm{H} 4 \mathrm{a}$ : 광고에 대한 감정적 평가(Aad)가 상표에 대한 감정적 평가(Ab)에 미치는 영향력은 관여도가 높은 집단보다 낮은 집단에서 더 클 것이다.

$\mathrm{H} 4 \mathrm{~b}$ : 광고에 대한 감정적 평가 $(\mathrm{Aad})$ 가 상표에 대한 감정적( $\mathrm{Ab}$ )에 미치는 영향력은 사전지식이 높은 집단보다 낮은 집단에서 더 클 것이다.

$\mathrm{H} 4 \mathrm{c}$ : 광고에 대한 감정적 평가(Aad)가 상표에 대한 감정적 평가(Ab)에 미치는 상대적 영향력은 사전지식이 낮은 집단보다 관여도가 낮은 집단에서 더 클 것이다.

그러나, 위와 같은 그들의 연구는 비록 $\mathrm{Aad}$ 에서 $\mathrm{Ab}$ 에 영향을 미치는 관계가 관여도를 고려하여 비교적 구체적으로 설명되었으나, $\mathrm{Aad}$ 에서 $\mathrm{Cb}$ 를 거쳐 $\mathrm{Ab}$ 로 가는 경로의 설명은 다소 미흡하다. 즉, 전술했듯이 소비자가 광고에 대해 가지고 있는 감정적 태도는 저관여일 경우 상표에 대한 감정적 태도로 뉩게 전이될 수 있다. 그러나 광고태도가 비록 우호적이더라도 소비자가 광고에서 제시된 상표를 적절히 평가할 수 있는 능력이 없다면 상표에 대한 적절한 인지적 평가가 수행되기 어렵고, 이에 따라 상표에 대한 태도를 형성하기가 어렵게 된다. 따라서 $\mathrm{Aad}$ 에서 $\mathrm{Cb}$ 를 거쳐 $\mathrm{Ab}$ 로 가는 경로는 관여도에 의한 조절적 역할보다는 소비자가 상표를 평가할 수 있는 능력과 관련된 사전지식이 더 큰 역할을 하리라 기대할 수 있다. 즉, 사전지식수준이 높은 소비자의 경우 상표에 대한 접근성과 진단성이 높기 때문에 Aad에서 $\mathrm{Cb}$ 로의 감정전이에 의한 태도형성보다는 광고에 노출된 인지적 반응들을 토대로 상표에 대한 우호적인 속성돌울 상세히 탐색함으로써 더 긍정적인 상표태도롤 형성할 것으로 예상된다.

$\mathrm{H} 5$ : 광고에 대한 감정적 평가(Aad)는 상표에 대한 인지적 평가 $(\mathrm{Cb})$ 에 유의적인 영향올 미칠 것이다.

$\mathrm{H} 5 \mathrm{a}$ : 광고에 대한 감정적 평가 $(\mathrm{Aad})$ 가 상표에 대한 인지적 평가(Cb)에 미치는 영향력은 관여도가 낮은 집단보다 높은 집단에서 더 클 것이다.

$\mathrm{H} 5 \mathrm{~b}$ : 광고에 대한 감정적 평가 $(\mathrm{Aad})$ 가 상표에 대한 인지적 평가 $(\mathrm{Cb})$ 에 미치는 영향력은 사전지식이 낮은 집단보다 높은 집단에서 더 클 것이다.

$\mathrm{H} 5 \mathrm{c}$ : 광고에 대한 감정적 평가(Aad)가 상표에 대한 인지적 평가 $(\mathrm{Cb})$ 에 미치는 상대적 영향력은 관여도가 높은 집단보다 사전지식이 높은 집단에서 더 클 것이다.

\subsection{3 감정적 평가와 행동의욕적 평가}

광고된 제품에 대한 감정적 평가 또는 상표에 대한 태도는 소비자둘의 상표에 대한 좋아함이나 싫어함 같은 정서적 느낌을 말한다. 또한 이러한 감정적 평가는 소비자에게 새로운 정보가 유입되었을 때 소비자가 이미 가지고 있는 사전신념과 반드시 비교될 필요는 없다. 왜냐하면 소비자가 톡정 상표에 대해 가지고 있는 태도 즉, 감정적 평가는 태도의 일차원적 견해에 따르면 주어진 단서에 대한 인지적 평가의 졀과물이기 때문이다. 따라서 이러한 평가는 소비자 개인의 분위기, 느낌 및 노출된 시점에서의 다른 감정들에 의해 영향을 받기가 쉽다(Burke and Edell 1989; Batra and Ray 1986; Lutz 1985).

또한, 주로 구매의도로 측정되는 행동의욕적 평가는 소비자들의 관여수준에 매우 
의존받기가 쉅다. 즉, 고관여 소비자들은 광고된 제품의 장점과 메시지 주장들을 인지적 측면에서 상세하게 살펴봄으로써 설득당하게 되고, 반면에 저관여 소비자들은 실행적 단서들, 반복, 정보원천의 호감성, 기타 감정적 측면을 소구하는 주변적 단서들을 통하여 설득 당하기가 눱다. 따라서 제품에 대한 사전지식이 높을 때 더 적극적으로 이루어지는 인지적 평가와는 다르게 상표에 대한 감정적 평가는 관여도에 의해서 더 크게 영향을 받을 것이다.

한편, 일반적으로 소비자는 고관여 상태에서 정보처리정도가 높을 때에 주로 중심경로를 통해서 태도를 형성하지만, 광고에서 주어진 정보들이 개인과 관련성이 없는 저관여 상태일 경우 주로 주변경로를 통해 정보를 처리하게 되므로 광고에서 제시되는 제품편익에 대한 구체적 정보보다는 광고분위기, 매력적인 모델 또는 음악과 같은 광고실행적 정보에 더 주의를 기울이게 된다. 그리고 이 때에는 주로 소비자의 광고 또는 상표에 대한 평가가 인지적 평가보다는 감정적 측면에서 평가가 이루어지기 뉩다. 따라서 소비자의 감정적 평가에 의한 구매의도의 형성은 관여도에 의해 영향을 받으리라 예상할 수 있다. 그러나 앞에서 기술했듯이 광고률 통해 자연스럽게 가질 수 있는 이러한 느낌(feelings)은 소비자가 이미 가지고 있는 사전지식과 반드시 연관될 필요는 없다. 왜냐하면 소비자의 감정적 평가반웅은 인지적 구조의 형성 또는 변화에 의한 반웅보다는 저관여 상태의 낮은 정보처리동기로 인한 주변단서에 의해 일시적인 태도의 형성이 주로 야기되기 때문이다. 물론 ELM에 의하면 정보처리능력이 부족할 경우 주변단서에 의한 정보처리가 이루어진다고 보고 있으나 이의 영향력은 매우 약하고, 또한 일부 연구에 의하면 감정적 반응의 영향력은 광고된 제품의 소비경험이 있는 경우보다 오히려 없는 경우에 더 큰 것으로 나타나고 있다(이학식 1991). 결과적으로 소비자의 상표에 대한 감정적 평가가 행동의욕적 평가에 미치는 영향력은 사전지식수준보다는 관여도수준에 더 큰 영향을 받을 것이라 예상할 수 있다.

$\mathrm{H6a}$ : 상표에 대한 감정적 평가(Ab)가 상표에 대한 행동의욕적 평가(Ib)에 미치는 영향력은 관여도가 높은 집단보다 낮은 집단에서 더 클 것이다.

$116 \mathrm{~b}$ : 상표에 대한 감정적 평가 $(\mathrm{Ab})$ 가 상표에 대한 행동의욕적 평가(Ib)에 미치는 영향력은 사전지식이 높은 집단보다 낮은 집단에서 더 클 것이다.

$\mathrm{H6c}$ : 상표에 대한 감정적 평가 $(\mathrm{Ab})$ 가 상표에 대한 행동의욕적 평가( $\mathrm{Ib})$ 에 미치는 상대적 영향력은 사전지식이 낮은 집단보다 관여도가 낮은 집단에서 더 클 것이다.

\section{3. 연구방법}

\section{1 피실험자}

본 연구의 가설 검정을 위한 자료의 수집은 편의표본추출법에 의하여 선정된 $\mathbf{J}$ 지역에 있는 남 여 대학생들을 대상으로 실시하였다. 먼저, 1 차 예비조사에서는 실헙 자극물의 
적절한 선정을 위하여 대학원 석- 박사 과정생들을 위주로 15 명의 피실헙자가 참여하였다. 그리고, 최공 제작된 광고를 대상으로 2차 본 조사가 수행되었는데, 응답에 참여한 인원은 총 380 명 이었고, 이중 불성실한 웅답올 제외하고 최종적으로 분석에 이용된 자료는 남 163 명, 여 197 명으로 총 360 명이었다.

\section{2 상표 및 제품의 선정}

본 연구에 이용될 제품 및 상표률 선정하기 위하여 마케팅 또는 소비자행동을 수강해 본 경험이 있는 대학원생들울 대상으로 1 차 예비조사가 실시되었다. 각 웅답자들에게는 인지와 감정적 측면을 동시에 소구할 수 있는 제품과 웅답자가 대학생이라는 점을 감안하여 이들에게 가장 적절한 제품을 선정토록 오구하였다. 또한 인지적인 소구내용뿐만 아니라 감정적인 소구내용도 고려하여(본 연구에서는 감정적 소구내용으로서 예비 피실헙자들과 토론을 거쳐 최근 많이 나타나고 있는 지역정서소구률 활용하였다) 선점하도록 하였는데 사전조사에서는 개인용 컴퓨터(PC)와 우유가 제시되었다. 그리고 이 두 제품에 대하여 가상의 상표로서 PC는 '유니컴' 을, 우유는 '초롱우유' 라는 브랜드를 부여하고 다시 예비 테스트를 실시하였다. 제품에 가상의 상표률 부착한 이유는 실제상표를 제시해 줌으로서 올 수 있는 선입견에 의한 편의(bias)의 제거 및 기타 기존의 정보나 개인적인 경험에 기인한 외생변수들의 효과를 방지하기 위함이었다.

2 차 논의 끝에 최종적으로 선정된 제품은 최근 각 지역별로 많이 이용되고 있는 컴퓨터(PC)가 선정되었다. 컴퓨터를 평가대상으로 고려한 이유는 컴퓨터가 비교적 복잡한 제품이면서도 소비자들에게 많은 지식과 관여도를 필요로 하고, 이에 따라 상대적으로 그 범위의 측정이 용이하다고 판단되었기 때문이다.

\section{3 광고자극 및 평가절차}

최종 본 조사에서 이용될 컴퓨터를 이용한 광고의 제작은 2 단계의 작업을 거쳐 진행되었는데, 먼저 대상 컴퓨터의 시각적인 면과 웅답자들에게 인지적인 판단을 요하도록 하는 10 개의 속성(예: 국내 벤처기업 1위의 컴퓨터 회사, 전국 91 개 서비스센터 완벽 가동, 400 여종의 엄격한 품질 테스트 통과, 사양대비 만족할 수 있는 가격, 동급제품보다 뛰어난 사양, 다양한 구매 특전 등)들이 제시되었다. 그리고 의 광고는 사전실험을 통하여 응답자들이 쉽게 이해가능한지의 여부와 제시된 인지적 속성들의 적절성 여부를 판단하였다. 그런 다음 이러한 과정을 통하여 작성된 광고에 다시 지역소구 내용(예: 유니컴 000 컴퓨터 탄생, 00 인을 위한 진정한 국민형 PC, 000 민께만 특별 한정판매!! 등)을 포합시키고 모의 피헙자들에게 지역소구정도를 옹답토록 하였다. 예비분석 결과 지역소구의 정도는 5.47(총 7점)로서 매우 높게 표현되어 있음을 알 수 있었다. 아울러 최종적으로 피실험자들에게 제시된 광고는 양질의 프린터를 활용하여 정교하게 인쇄함으로서 실제의 인쇄광고 못지 않은 효과룰 보이도록 하였으며, 설문 응답절차에 따라 광고에 노출될 때에는 컬러광고의 효과률 극대화하기 위하여 빔 프로젝터(beam projector)로 약 3 분간 제시되었다.

설문 응답은 크게 두 가지 단계에 걸쳐 실시되었다. 피실헙자들에게는 먼저 자극물의 
광고노출로 인한 응답상의 오류롤 방지하기 위하여, 광고가 제시되기 전에 평소 본인이 가지고 있는 컴퓨터에 관한 사전지식과 관여도의 측정문항들이 제시되었다. 각 문항들에 대한 응답을 완료한 후 이들에게 약 3 분 정도 인지적 측면과 감정적 측면이 혼합된 최종 광고물을 보도록 하였다. 그런 다음 최종적으로 웅답자들에게 제시된 광고물에 대하여 인지적, 감정적, 행동의욕적 평가를 작성토록 하였다. 끝으로 관여수준 및 사전지식 수준별 집단의 구분시 지역정서의 차이로 인한 광고효과검중의 오차률 방지하기 위하여 개인의 지역정서 경향을 묻는 문항과 인구통계변수들이 제시되었다. 설문에 대한 피실험자들의 정확한 옹답을 유도하기 위하여 응답자들에게는 추후 추첨올 통하여 문화상품권을 제공한다고 약속하였다.

\section{4 변수의 측정}

\subsection{1 사전지식}

사전지식(prior knowledge)을 측정하는 변수로는 선행연구들(Alba and Hutchinson 1987; Brucks 1986; Park, Mother sbaugh and Feick 1994; Rao and Sieben 1992)에서 활용되었던 객관적 지식(object ive knowledge)과 주관적 지식 (subject ive knowledge)으로 측정하였다. 소비자의 사전지식 중 객관적 지식은 전문지식 또는 제품과 관련된 업무률 수행할 수 있는 능력과 매우 밀접하게 관련되어 있다. 본 연구에서는 선행연구들울 토대로 개인용 컴퓨터에 관한 객관적 지식수준올 15 개 문항으로 측정하였다(예: 나는 컴퓨터를 구매한 적이 있다, 컴퓨터 범죄를 예방하기 위해서는 한 번 설정한 패스워드는 가급적 변경하지 않는다, $1 \mathrm{~GB}$ 는 $1024 \mathrm{~KB}$ 이다, Rom은 데이터를 읽고 쓸 수 있으며, 전원공급이 중단되면 데이터가 지워진다, 산술논리 연산장치와 제어 장치는 중앙처리장치의 구성요소이다 등). 그리고 이러한 각각의 객관적 지식의 문항들은 정답올 기준으로 합산 처리되어 단일항목으로 이용되었다.

또한 주관적 지식은 소비자가 정보탐색을 포함하여 제품관련된 업무를 수행할 수 있는 자신감을 가지고 있음을 의미한다(Duncan and Olshavsky 1982; Park and Lessig 1981). 본 연구에서는 주관적 지식수준의 측정변수로 Brucks(1985), Park et al.(1994), 이학식과 김종성(1999)의 연구에서 활용된 문항듈을 토대로 개인적으로 다른 동료에 비해 특정 제품올 잘 알고 있다고 지각하는 정도와 그 제품에 친숙한 정도률 “ 전혀 그렇지 않다 매우 그렇다" 의 7점 척도로 측정하였다.

\section{4 .2 관여도}

본 연구의 광고물에서 제시된 개인용 컴퓨터에 대해 중요하게 생각하는 정도 또는 관심의 정도를 나타내는 관여도는 Zaichkowsky(1985, 1994)의 PII(Personal Involvement Inventory)및 선행연구(이학식 1991; Park and Young 1986)들에서 주로 활용된 제품의 지속적 관여도를 중심으로 본 연구를 위하여 보다 적절하다고 판단되는 8 개 항목을 이용하여 측정하였다. 구체적으로 개인용컴퓨터는 나에게 “중요하다/중요하지 않다, 유용하지 않다/유용하다, 필요하지 않다/필요하다, 의미가 작은 제품이다/의미가 큰 제품이다, 하찮은 것이다/중대한 것이다" 등의 7점 어의차이척도(semantic differential scale)로 측정하였다. 


\section{4 .3 광고평가와 상표평가}

광고에 대한 태도(즉, 광고에 대한 감정적 평가: Aad)는 선행연구인 이학식(1991), Gardner(1985), MacKenzie, Lutz and Belch(1986), Michell and 0lson(1981) 등에서 활용된 내용을 토대로 4 개의 어의차이척도를 이용하여 7 점 척도로 측정하였다예: 나는 이 광고가(는) ' 매우 좋다/매우 싫다', '전혀 마음에 들지 않는다/매우 마옴에 든다' , ' 부정적인 느낌을 준다/긍정적인 느낌올 준다' ' ' 매우 나쁘다/매우 줗다' J.

또한 상표에 대한 태도(즉, 상표에 대한 감정적 평가: Ab)는 이학식(1991), Belch(1982), MacKenzie, Lutz and Belch(1986) 등의 연구에서 사용된 항목들을 토대로 네 개의 7점 어의차이 척도를 이용하여 측정하였다[예: 나는 이 제품에(이) ' 전혀 호감이 가지 않는다/매우 호감이 간다' , '전혀 시선이 가지 않는다/매우 시선이 간다' , ' 전혀 마음에 들지 않는다/매우 마음에 든다', '매우 부정적이다/매우 긍정적이다' J.

한편, 상표에 대한 인지적 평가 $(\mathrm{Cb})$ 는 기존의 선행연구들(이학식, 정주훈, 이호배 1998; MacKenzie, Lutz and Belch 1986)에서 주로 상표에 대한 인지적 반옹올 개방형 질문(open-ended question)을 할용하여 측정되었다. 그러나 본 연구에서는 태도형성의 일차원적인 견해에 입각하여 각각의 선형관계에 대한 사전지식과 관여도의 상대적 효과를 보는 것이 주목적이므로 선행 연구인 Okechuku(1992)의 인지적 평가 내용을 토대로 7점의 어의차이척도률 이용하여 측정하였다. 측정에 이용된 문항은 다음과 같다. 나는 이 제품을 전혀 신뢰할 수 없다/매우 신뢰한다, 나는 이 제품이 전혀 정교하지 못할 것 같다/매우 정교할 것 같다, 나는 이 제품의 품질이 매우 떨어질 것 같다/품질이 매우 우수할 것 같다, 나는 이 제품이 기술적으로 매우 열악한 제품 같다/기술적으로 매우 우수한 제품 같다. 나는 이 제품의 디자인이 매우 떨어지는 것 같다/매우 우수한 것 같다.

\subsection{4 구매의도}

상표에 대한 구매의도(즉, 행동의욕적 평가: $\mathrm{Ib}$ )는 선행연구(이학식 1991; MacKenzie, Lutz and Belch 1986; Okechuku 1992)를 토대로 4개의 7점척도(나는 기회가 있으면 이 제품을 '절대로 사지 않겠다/반드시 사보고 싶다', '전혀 소유하고 싶지 않다/반드시 소유해보고 싶다', '전혀 사용해보고 싶지 않다/반드시 사용해보고 싶다', 당신에게 기희가 있다면 이 제품을 이용할 가능성은 '전혀 없다 매우 많다' )에 의하여 측정하였다.

\section{4. 분석결과}

본 연구에서는 다항목으로 촉정된 척도돌의 신뢰성과 타당성을 검토하기 위하여 Gerbing and Anderson(1988)이 제안한 척도정제 절차를 참조하였다. 먼저 각 구성개넘의 측정지표로서 활용된 다항목들에 대하여 내적 일관성(internal consistency)과 단일차원성(unidimensionality)을 검토하였다. 그리고 분석결과 각 구성개념들에 대하여 단일차원성을 구성하지 못하는 변수들을 제외하고, 나머지 변수들을 대상으로 집중타당성(convergent validity)과 판별타당성(discriminant validity)을 검토하였다. 


\section{1 신뢰성과 단일차원성 분석}

측정변수들의 내적 일관성과 단일차원적 타당성울 검토하기 위하여 각 차원별 측정항목들의 신뢰도(reliability) 및 확인적 요인분석(confirmatory factor analysis)을 실시하였다. 그리고 이와 같은 분석과정에서 신뢰성과 단일차원성을 구성하지 못하는 변수들은 제외시켰다. 그 결과는 <표 1 과 같다.

<표 1> 측정변수들의 신뢰성 및 단일차원성 분석 결과

\begin{tabular}{|c|c|c|c|c|c|c|c|c|c|}
\hline 구성개념 & $\begin{array}{c}\text { 최초 } \\
\text { 항목수 }\end{array}$ & $\begin{array}{c}\text { 신뢰계수 } \\
(\alpha)\end{array}$ & $\begin{array}{l}\text { 신뢰성 } \\
\text { 분석후 } \\
\text { 핮목수 } \\
\end{array}$ & $\begin{array}{l}\text { 확인요인 } \\
\text { 분석후 } \\
\text { 학목수 }\end{array}$ & GFI & RMSR & NFI & $x^{2}$ & $\mathrm{P}$ 값 \\
\hline $\mathrm{Ib}^{\mathrm{a}}$ & 4 & .8773 & 4 & 3 & - & - & - & - & - \\
\hline $\mathrm{Ab}$ & 5 & .8787 & 5 & 4 & .98 & .025 & .99 & 11.15 & .00 \\
\hline Aad & 4 & .8828 & 4 & 4 & .94 & .038 & .95 & 40.46 & .00 \\
\hline $\mathrm{Cb}$ & 5 & .8315 & 4 & 4 & .97 & .045 & .96 & 23.19 & .00 \\
\hline $\mathrm{NV}^{\mathrm{c}}$ & 8 & .9392 & 8 & - & - & - & - & - & - \\
\hline $\mathrm{PK}^{\mathrm{bc}}$ & 2 & .7498 & 2 & - & - & - & - & - & - \\
\hline
\end{tabular}

$\mathrm{a}: \mathrm{Ib}=$ 상표에 대한 행동의욕적 평가(lb의 적합도 지수는 perfect으로 나타나 제시하지 않음)

$\mathrm{Ab}=$ 상표에 대한 감정적 평가, $\mathrm{Aad}=$ 광고에 대한 감정적 평가, $\mathrm{Cb}=$ 상표에 대한 인지적 평가,

b: 사전지식(prior knowledge)의 경우 주관적 지식 2문항(객관적 지식은 15 문항은 신뢰도 분석 제외)

c: 관여도와 사전지식은 집단구분 변수이므로 확인요인분석 대상에서 제의함

<표 1>의 신뢰성 분석 결과 Cronbach's alpha값은 상표에 대한 행동의욕적 평가(.8773), 상표에 대한 감정적 평가(.8787), 광고에 대한 감정적 평가(.8828), 상표에 대한 인지적 평가(.8315)로서 상표에 대한 인지적 평가 $(\mathrm{Cb})$ 에서 제외된 한 문항(디자인이 매우 떨어지는 것 같다/매우 우수한 것 같다)을 제외하고 각 측정문항듈간에 내적 일관성이 있음을 확인하였다. 또한 관여도와 사전지식의 경우 신뢰계수값이 각각 .9392와 .7498로서 역시 내적 일관성이 있음을 확인하였다.

한편, 신뢰도 분석에서 신뢰성이 인정된 $\mathrm{Ib}, \mathrm{Ab}, \mathrm{Aad}, \mathrm{Cb}$ 의 측정항목들을 대상으로 단일차원성올 검토하기 위하여 각 구성개념(construct)별로 확인적 요인분석(confirmatory factor analysis)를 실시하였다. 그리고 이 분석과정에서 각 구성개념별로 단일차원성을 저해시키는 항목들을 제거하였는데 상표에 대한 행동의욕적 평가 중 한 문항(전혀 사용해보고 싶지 않다/반드시 사용해보고 싶다)과 상표에 대한 감정적 평가 척도 중 한 문항(매우 싫다/매우 좋다)이 제거되었다. 관여도와 사전지식은 본 연구의 연구가설 검토를 위한 집단구분 변수이므로 확인적 요인분석의 대상에서 제외하였다. 각 단계별 항목구성의 최적상태를 도출하기 위한 적합도 평가 기준들은 GFI(Goodness of Fit Index: $\geq .90$ ), RMSR(Root Mean Square Residual: $\leq .05$ ), NFI(Normed Fit Index: $\geq .90), x^{2}$ (작을수록 바람직함), $x^{2}$ 에 대한 $p^{-v a l u e(>.05) ~ ㄷ ㅡ ㅇ ㅇ ㅗ ㄹ ~ ㅇ ㅣ ㅇ ㅛ ㅇ ㅎ ㅏ ㅇ ㅕ ㅆ ㄷ ㅏ(H a i r ~ e t ~ a l . ~ 1995) . ~}$ 


\section{2 집중타당성과 판별타당성 분석}

척도들의 집중타당성(convergent validity)과 판별타당성(discriminant validity)을 검토하기 위하여 신뢰성 검토에서 부적절한 항목으로 판정된 설문항목들을 제외하고 나머지 항목들을 이용하여 본 모델에 포함둴 모든 구성개념들 전체의 측정모형(measurement model)을 분석하였다. 분석에 이용된 자료는 상관행렬자료(correlation matrix data) 이었으며, Lisrel 8.30 (Jõ reskog and Sö rbom 1999) 프로그램의 최우추정 (maximum likelihood estimation) 방법을 이용하였다. 이 분석에서는 최적의 측정모형을 확보하기 위하여 수정지수를 참고로 일부 문항들(Cb 1문항, Ib 1 문항)이 제거되었는데, 이 때 측정항목들의 과대한 제거를 방지하기 위하여 적합도(GFI, AGFI) 증가율이 추가적인 항목 제거에 따라 큰 폭으로 변하지 않는 수준까지만 척도롤 정제하였다. 그 이유는 적합도 확보를 위해 측정항목들을 다수 제거할 경우 모델의 추정에 대한 정보의 손실이 발생할 수 있기 때문이다. 따라서 이롤 최소화할 필요가 있는 수준까지만 척도 정제가 수행되었고, 이 과정을 거쳐 분석에 투입될 전체 측정모형울 확정하였는데 그 결과는 <표 2 와 같다.

<표 2> 전체구성개념들에 대한 확인적 요인분석 결과 ${ }^{a}$

\begin{tabular}{|c|c|c|c|c|c|}
\hline 구성개늗 & 및 척도 ${ }^{b}$ 표준화돈 & 요인부하량 & $\mathrm{t}$ 값 & 구성개념 신뢰도 & 분산추출값 \\
\hline \multirow{2}{*}{ Ib } & Ib1 & .88 & 16.78 & \multirow{2}{*}{.7514} & \multirow{2}{*}{.6023} \\
\hline & Ib2 & .96 & 15.29 & & \\
\hline \multirow{4}{*}{$\mathrm{Ab}$} & $\mathrm{Ab} 1$ & .93 & 17.68 & \multirow{4}{*}{.8756} & \multirow{4}{*}{.6503} \\
\hline & $\mathrm{Ab} 2$ & .92 & 16.58 & & \\
\hline & $\mathrm{Ab} 3$ & .84 & 19.45 & & \\
\hline & $\mathrm{Ab} 4$ & .80 & 17.86 & & \\
\hline \multirow{4}{*}{ Aad } & Aad 1 & .87 & 17.59 & \multirow{4}{*}{.8843} & \multirow{4}{*}{.6580} \\
\hline & Aad2 & .77 & 18.57 & & \\
\hline & Aad3 & .89 & 18.09 & & \\
\hline & Aad4 & .73 & 17.86 & & \\
\hline \multirow{3}{*}{$\mathrm{Cb}$} & $\mathrm{Cb} 1$ & .88 & 17.77 & \multirow{3}{*}{.8538} & \multirow{3}{*}{.6609} \\
\hline & $\mathrm{Cb} 2$ & .94 & 18.05 & & \\
\hline & $\mathrm{Cb} 3$ & .86 & 17.25 & & \\
\hline
\end{tabular}

$a: x^{2}=173.36(d . f=59, p=.00), G F I=.93, A G F I=.89$, RMSR $=.037, N F I=.94$

$\mathrm{b}$ : $\mathrm{Ib}=$ 상표에 대한 행동의욕적 평가, $\mathrm{Ab}=$ 상표에 대한 감정적 평가, $\mathrm{Aad}=$ 광고에 대한 감정적 평가 $\mathrm{Cb}=$ 상표에 대한 인지적 평가, 가 척도는 분석에 투입된 쵝종 항목들임

c: 구성개념 신뢰도(construct reliability) $=(\text { 표준 부하량의 합) })^{2} /\left(\right.$ (표준 부하량의 합) $^{2}+$ 측정오차의 합 $\}$

$\mathrm{d}$ : 분산추출값(variance extracted) = 표준부하량 게곱의 합 / (표준 부하량 제곱의 합 + 측정오차의 합)

<표 $2>$ 에 나타난 바와 같이 전체 구성개념올 이용한 측정모형의 분석결과 $\mathrm{x}^{2}=$ $173.36(\mathrm{~d} . \mathrm{f}=59, \mathrm{p}=.00), \mathrm{GFI}=.93, \mathrm{AGFI}=.89, \mathrm{RMSR}=.037, \mathrm{NFI}=.94$ 로서 $\mathrm{x}^{2}$ 값을 제외하고 기타 적합도 기준들을 만족시키고 있는 것으로 나타났다. 또한 4 개의 구성개념둘에 대한 각 척도측들의 표준요인부하량(standardized loadings)도 모두 유의적으로 나타나( $t>15.29)$ 
집중타당성이 있음을 확인하였다. 그리고 각 척도들이 해당 구성개념들에 대하여 대표성을 갖는지를 평가하기 위하여 구성개념 신뢰도(construct reliability)와 분산추출값(average variance extracted)을 계산하였다. 그 결과 각 구성개념의 신뢰도가 일반적 추천치인 .70보다 높으며(Hair et al. 1995), 분산 추출값은 추천값인 .50보다 높게 나타나(Fornell and Larcker 1981) 본 연구에 사용되는 측정항목들은 해당 구성개념에 대한 대표성을 갖는다고 할 수 있다.

한편 연구 구성개념들간의 판별타당성을 살펴보기 위하여 각 개념들간의 상관관계행렬( $\phi$ matrix)을 검토하였다(Bagozzi 1981). <표 3>과 같이 각 구성개념들간의 상관관계계수가 $\Phi$ 계수의 신뢰구간( $\phi \pm 2$ s.e. $)$ 내에 1 을 초과하고 있지 않아 전체 구성개념간에 판별타당성이 있는 것으로 확인되었다.

<표 3> 전체 구성개념들간의 상관관계 행렬 (\$ matrix)

\begin{tabular}{ccccc}
\hline 구성개념 & $\mathrm{Ib}$ & $\mathrm{Ab}$ & $\mathrm{Aad}$ & $\mathrm{Cb}$ \\
\hline $\mathrm{Ib}$ & 1.00 & & & \\
$\mathrm{Ab}$ & 0.84 & 1.00 & & \\
& $(0.03)$ & 0.69 & & \\
$\mathrm{Aad}$ & 0.64 & $(0.03)$ & 1.00 & \\
& $(0.04)$ & 0.76 & 0.52 & 1.00 \\
$\mathrm{Cb}$ & 0.69 & $(0.03)$ & $(0.05)$ & \\
\hline
\end{tabular}

* : ( )안은 표준오차임

\section{3 연구가설의 검중}

\subsection{1 연구모형의 적합도 평가}

본 연구에서 설정한 제 가설들(주효과와 조절효과)의 경로비교률 위해 앞서 척도 정제과정에서 확인된 제 문항들을 단일항목화하여 광고에 대한 감정적 평가, 상표에 대한 인지적 평가, 상표에 대한 감정적 평가 그리고 상표에 대한 행동의욕적 평가간의 인과적 관계를 추정하였다. 전체 구조모형(overall model)의 모수는 최우추정(Maximum Likelihood) 방법올 이용하였다. 구조모델 검중결과 모형의 적합도는 $\mathrm{x}^{2}=26.00(\mathrm{~d} . \mathrm{f}=2, \mathrm{p}=.00), \mathrm{GFI}=.97$, $\mathrm{AGFI}=.83, \mathrm{RMSR}=.050, \mathrm{NFI}=.96$ 으로서 $\mathrm{x}^{2}$ 값의 유의도를 제외하고 나머지 적합도 지수들이 모두 .8을 초과하고 있어 가설올 검중하는데 무리가 없을 것으로 판단되었다.

\subsection{2 연구가설의 검토(주효과 분석)}

구조모형의 각 경로에 대한 전체 추정결과는 <표 4>, <그림 1>과 같다. 
<표 4> 구성개념둘간의 관계 및 가설 요약

\begin{tabular}{lcccccccc}
\hline 가설 & 경로 & 경로명칭 경로계수 & 표준오차 & $\mathrm{t}$ 값 & $\mathrm{p}$ 값 & 채택여부 \\
\hline $\mathrm{H} 1$ & $\mathrm{Cb} \rightarrow \mathrm{Ab}$ & $\beta_{21}$ & .47 & .04 & 11.81 & $\mathrm{p}<.01$ & 0 \\
$\mathrm{H} 2$ & $\mathrm{Ab} \rightarrow$ & $\mathrm{Ib}$ & $\beta_{32}$ & .68 & .04 & 17.71 & $\mathrm{p}<.01$ & 0 \\
$\mathrm{H} 4$ & $\mathrm{Aad} \rightarrow$ & $\mathrm{Ab}$ & $\gamma_{21}$ & .39 & .04 & 9.85 & $\mathrm{p}<.01$ & 0 \\
$\mathrm{H} 5$ & $\mathrm{Aad} \rightarrow \mathrm{Cb}$ & $\gamma_{11}$ & .45 & .05 & 9.59 & $\mathrm{p}<.01$ & 0 \\
\hline
\end{tabular}

$\mathrm{a}$ : $\mathrm{Ib}=$ 상표예 대한 행동의욕적 평가, $\mathrm{Ab}=$ 상표에 대한 감정적 평가, $\mathrm{Aad}=$ 광고에 대한 감정적 평가 $\mathrm{Cb}=$ 상표에 대한 인지적 평가

각 경로에 대한 주효과(main effects)분석 결과 상표에 대한 인지적 평가에서 상표에 대한 감정적 평가(.47), 상표에 대한 감정적 평가에서 상표에 대한 행동의욕적 평가(.68), 광고에 대한 감정적 평가에서 상표에 대한 감정적 평가(.39), 광고에 대한 감정적 평가에서 상표에 대한 인지적 평가(.45)의 제 경로들이 모두 유의적으로 긍정적(+)인 효과를 미치는 것으로 나타났다. 따라서 가설 $\mathrm{H} 1, \mathrm{H} 2, \mathrm{H} 4, \mathrm{H} 5$ 는 지지되었다.

<그립 1> Overall Model 분석결과

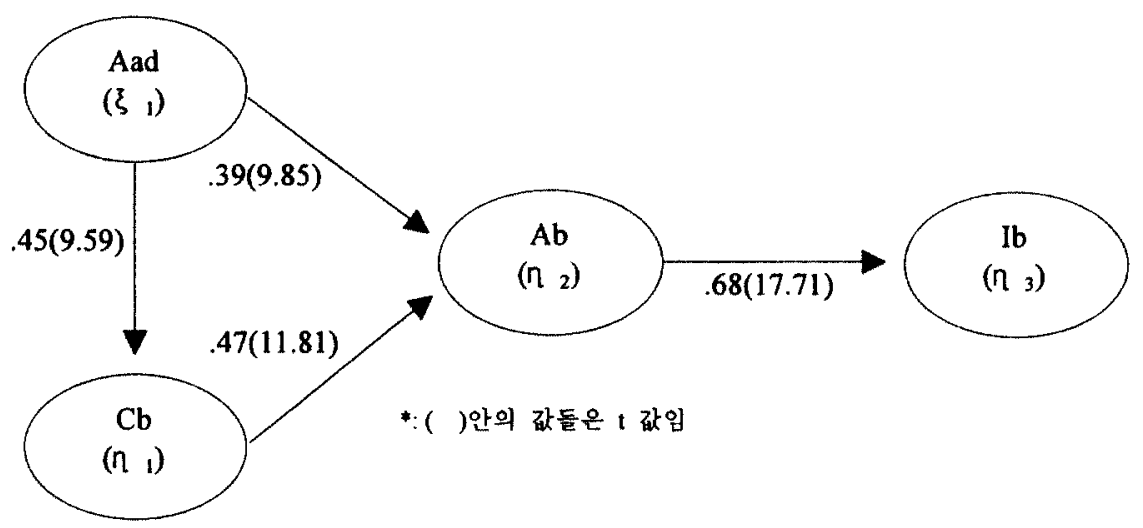

\subsection{3 연구가설의 검토(조절효과 분석)}

앞에서 살펴본 주효과 분석을 토대로 소비자의 사전지식과 관여도간의 역할 및 관계에 따라 각 경로들이 어떻게 차이가 나는지를 검토하기 위하여 사전지식은 평균 $M=12.50$ 을 기준으로 각 집단수의 균형울 고려하여 높은 지식보유 집단(high prior knowledge, $\mathrm{M}_{176}=15.59$ ), 낮은 지식보유 집단( low prior knowledge, $\mathrm{M}_{184}=9.55$ )으로 그리고 관여도는 평균 $M=5.89$ 를 기준으로 고관여 집단(high involvement, $M_{200}=6.58$ ), 저관여 집단(low involvement, $\left.M_{160}=5.05\right)$ 으로 구분하였다. 그리고 이들 간의 차이는 <표 5>에 제시된 바와 같이 유의적인 것으로 나타났다. 
<표 5> 각 실험집단별 수준에 대한 분산분석

\begin{tabular}{|c|c|c|c|c|c|c|}
\hline & 수준구분요인 & $\begin{array}{c}\text { 자승합 } \\
\text { (SS) }\end{array}$ & $\begin{array}{c}\mathrm{df} \\
(\mathrm{n}=360)\end{array}$ & $\begin{array}{c}\text { 평균자숭 } \\
\text { (MS) }\end{array}$ & $F$ 값 & $P$ 값 $^{2}$ \\
\hline 사 & 집단간 분산 & 3284.026 & 1 & 3284.026 & 809,440 & $.000 * * *$ \\
\hline $\begin{array}{l}\text { 전 } \\
\text { 지 }\end{array}$ & 집단내 분산 & 1452.463 & 358 & 4.057 & & \\
\hline 식 & 합계 & 4736.489 & 359 & & & \\
\hline 관 & 집단간 분산 & 207.104 & 1 & 207.104 & 553,437 & $.000 * * *$ \\
\hline 여 & 집단내 분산 & 133.969 & 358 & .374 & & \\
\hline 도 & 합계 & 341.072 & 359 & & & \\
\hline
\end{tabular}

$a: * * *$ p $<.01$

한편, 위에서 분류된 각 집단들을 토대로 사전지식과 관여도에 따른 상표에 대한 인지적 평가와 상표에 대한 감정적 평가와의 관계 $(\mathrm{H} 3 \mathrm{a}, \mathrm{H} 3 \mathrm{~b}, \mathrm{H} 3 \mathrm{c})$, 광고에 대한 감정적 평가와 상표에 대한 감정적 평가의 관계 $(\mathrm{H} 4 \mathrm{a}, \mathrm{H} 4 \mathrm{~b}, \mathrm{H} 4 \mathrm{c})$, 광고에 대한 감정적 평가와 상표에 대한 인지적 평가의 관계( $\mathrm{H} 5 \mathrm{a}, \mathrm{H} 5 \mathrm{~b}, \mathrm{H} 5 \mathrm{c})$, 상표에 대한 인지적 평가와 상표에 대한 행동의욕적 평가와의 관계 $(\mathrm{H} 6 \mathrm{a}, \mathrm{H} 6 \mathrm{~b}, \mathrm{H} 6 \mathrm{c})$ 를 검증하기 위하여 카이자승 $\left(\mathrm{x}^{2}\right)$ 검증에 의한 각 집단간의 경로계수를 비교하였다. 이는 검증하고자 하는 두 집단간의 모든 경로를 동일하게 한 후 비교하고자 하는 하나의 경로에 대한 $x^{2}$ 값올 비교하는 방법으로서, 이 때 $x^{2}$ 값의 차이가 자유도가 1 일 때 유의적인지의 여부에 따라 두 집단간의 경로계수값이 차이가 있는지 없는지를 결정하게 된다(이재록 \& 이학식 1998; MacKenzie and Spreng 1992). 이하에서는 이와 같은 방식에 따라 사전지식과 관여도 각각의 상대적 영향력을 비교하였다.

\subsubsection{1 $\mathrm{Cb}$ 와 $\mathrm{Ab}$ 의 관계에 관한 조절효과 분석}

앞서 검토된 가설 3 은 상표에 대한 인지적 평가가 상표에 대한 감정적 평가에 유의적인 영향력이 있음을 확인하였다. 이를 바탕으로 만약 이러한 영향력이 정보처리능력 관점에서의 사전지식과 정보처리동기 관점에서의 관여도가 각각 다률 경우 어떻게 영향올 받는지률 검토하여 보았다. 그 결과는 <표 6>과 같다.

<표 6> 사전지식과 관여도에 따론 $\mathrm{Cb} \rightarrow \mathrm{Ab}$ 경로의 $\mathrm{x}^{2}$ 차이 검증 결과

\begin{tabular}{|c|c|c|c|c|c|c|c|}
\hline \multirow{2}{*}{ 가설 } & \multirow{2}{*}{ 경로 } & \multirow{2}{*}{ 경로 명칭 } & \multirow{2}{*}{ 조절변수 } & \multicolumn{2}{|c|}{ 경로계수 ( $\mathrm{t}$ 값) } & \multirow{2}{*}{$\begin{array}{c}x^{2} \text { 차이 }{ }^{a} \\
\text { 검중 }\end{array}$} & \multirow[t]{2}{*}{ 채택여부 } \\
\hline & & & & $\ln w$ & hioh & & \\
\hline $\mathrm{H} 3 \mathrm{a}$ & & & PK & $.42(7.97)$ & $.55(10.32)$ & $3.79 *$ & 0 \\
\hline $\mathrm{H} 3 \mathrm{~b}$ & $\mathrm{Cb} \rightarrow \mathrm{Ab}$ & $\beta_{21}$ & INV & $.39(6.99)$ & $.53(10.52)$ & .53 & $x$ \\
\hline $\mathrm{H} 3 \mathrm{c}$ & & & $P K \times I N V^{b}$ & $.56(11.45)$ & $.55(11.82)$ & .03 & $x$ \\
\hline
\end{tabular}

$\mathrm{a}: * \mathrm{p}<.1, * * \mathrm{p}<.05, * * * \mathrm{p}<.01$

$\mathrm{b}: \mathrm{PK} \times \mathrm{INV}$ 는 각각 높은 사전지식 집단과 높은 관여도 집단 모델의 비교임 
가설3a는 상표에 대한 인지적 평가에서 상표에 대한 감정적 평가로의 영향력은 사전지식수준이 낮은 집단보다 높은 집단에서 더 쿨 것으로 예상하였다. 두 집단의 경로비교 결과 낮은 집단보다 높은 집단에서 더 크게 나타나 $\mathrm{H} 3 \mathrm{a}$ 는 한계적으로 지지됨을 확인하였다 $\left(\mathrm{x}^{2}=3.79, \mathrm{p}<.1\right)$. 그러나 관여도에 따라서는 두 집단의 경로가 유의적인 차이를 보이지 않았고(H3b), 상대적으로 관여도가 높은 집단의 영향력 보다 사전지식이 높은 집단의 영향력이 더 클 것이라는 가설 $\mathrm{H} 3 \mathrm{c}$ 도 지지되지 못하였다.

\subsubsection{Aad와 $\mathrm{Ab}$ 의 관계에 관한 조절효과 분석}

가설 4에서 광고에 대한 감정적 평가가 상표에 대한 감정적 평가에 유의적인 영향을 미치는 것으로 나타났다. 이률 바탕으로 사전지식과 관여도의 역할율 살펴보면 <표 $7>$ 과 같다.

<표 7> 사전지식과 관여도에 따른 $\mathrm{Aad} \rightarrow \mathrm{Ab}$ 경로의 $\mathrm{X}^{2}$ 차이 검증 결과

\begin{tabular}{|c|c|c|c|c|c|c|c|}
\hline \multirow{2}{*}{ 가설 } & \multirow{2}{*}{ 경로 } & \multirow{2}{*}{ 경로명칭 } & \multirow{2}{*}{ 조절변수 } & \multicolumn{2}{|c|}{ 경로계수( $\mathrm{t}$ 값) } & \multirow{2}{*}{$\begin{array}{c}x^{2} \text { 차이 }{ }^{a} \\
\text { 검중 }\end{array}$} & \multirow{2}{*}{ 채택여부 } \\
\hline & & & & lnw & high & & \\
\hline $\mathrm{H} 4 \mathrm{a}$ & & & PK & $.38(7.21)$ & $.41(7.69)$ & .86 & $x$ \\
\hline $\mathrm{H} 4 \mathrm{~b}$ & $A a d \rightarrow A b$ & $\gamma_{21}$ & INV & $.38(6.77)$ & $.40(7.80)$ & $4.76 * *$ & $x$ \\
\hline $\mathrm{H} 4 \mathrm{c}$ & & & $\mathrm{PK} \times \mathrm{INV}^{\mathrm{b}}$ & $.41(7.16)$ & $.43(7.02)$ & .09 & $x$ \\
\hline
\end{tabular}

$a: * p<, 1, * * p<.05, * * 0<.01$

$\mathrm{b}: \mathrm{PK} \times \mathrm{INV}$ 는 각각 낮은 사전지식 집단과 낮은 관여도 집단 모델의 비교임

가설 $4 \mathrm{a}$ 는 광고에 대한 감정적 평가에서 상표에 대한 감정적 평가로의 영향력이 사전지식이 높은 집단보다 사전지식이 낮은 집단예서 더 클 것이라 예상하였다. 두 집단의 경로계수들의 비교 결과 낮은 집단과 높은 집단간에 유의적인 차이가 없는 것으로 나타났다. 반면에 관여도의 경우 관여수준이 높은 집단보다 낮은 집단에서 $\mathrm{Aad} \rightarrow \mathrm{Ab}$ 경로의 영향력이 더 클 것으로 예상하였는데 기대와 다르게 관여도가 높은 집단에서 더 큰 영향력이 있는 것으로 나타났다 $\left(\mathrm{x}^{2}=4.76, \mathrm{p}<.05\right)$. 한편, $\mathrm{Aad} \rightarrow \mathrm{Ab}$ 경로에 대한 사전지식과 관여도의 상대적 효과 비교는 사전지식이 낮은 집단과 관여도가 낮은 집단간에 유의적인 차이가 없는 것으로 나타났다. 따라서 가설 $\mathrm{H} 4 \mathrm{a}, \mathrm{H} 4 \mathrm{~b}, \mathrm{H} 4 \mathrm{c}$ 는 지지되지 못하였다.

\subsubsection{Aad와 $\mathrm{Cb}$ 의 관계에 관한 조절효과 분석}

가설 5 는 주효과 분석결과 광고에 대한 감정적 평가가 상표에 대한 인지적 평가에 유의적인 영향력을 미치는 것에 관한 것이다. 이를 바탕으로 사전지식수준과 관여도수준이 각각 다를 경우 어떻게 영향을 받는지률 검토하여 보았다. 그 결과는 <표 $8>$ 과 같다.

가설 $5 \mathrm{a}$ 는 광고에 대한 감정적 평가가 상표에 대한 인지적 평가로 영향을 미치는데 사전지식이 높은 집단이 사전지식이 낮은 집단보다 영향력이 더 클 것이라 예상하였다. 두 집단의 경로비교 결과 사전지식이 높은 집단이 낮은 집단보다 더 크게 영향력이 있음을 확인하였다 $\left(\mathrm{x}^{2}=4.53, \mathrm{p}<.05\right)$. 그러나 관여도의 경우 관여수준이 낮은 집단보다 높은 집단에서 $\mathrm{Aad} \rightarrow \mathrm{Cb}$ 경로의 영향력이 더 클 것으로 예상하였는데 기대와 다르게 유의적인 차이를 발견하지 못하였다. 따라서 가설 $\mathrm{H} 5 \mathrm{a}$ 는 지지되었으나 $H 5 \mathrm{~b}$ 는 지지되지 못하였다. 
한편, $\mathrm{Aad} \rightarrow \mathrm{Cb}$ 경로에 대한 사전지식과 관여도의 상대적 효과 비교는 사전지식이 높은 집단에서의 경로에 대한 영향력이 관여도가 높은 집단에서의 영향력보다 더 클 것으로 기대하였다. 분석결과 예상했던 대로 사전지식이 높은 집단이 관여도가 높은 집단보다 경로에 대한 영향력이 더 큼을 확인하였다 $\left(x^{2}=3.90, p<.05\right)$. 따라서 가설 $\mathrm{H} 5 \mathrm{c}$ 는 지지되었다.

<표 8> 사전지식과 관여도에 따론 $\mathrm{Aad} \rightarrow \mathrm{Cb}$ 경로의 $\mathrm{x}^{2}$ 차이 검증 결과

\begin{tabular}{|c|c|c|c|c|c|c|c|}
\hline \multirow{2}{*}{ 가설 } & \multirow{2}{*}{ 경로 } & \multirow{2}{*}{ 경로명칭 } & \multirow{2}{*}{ 조절변수 } & \multicolumn{2}{|c|}{ 경로계수 ( $\mathrm{t}$ 값) } & \multirow{2}{*}{$\begin{array}{c}x^{2} \text { 차이 }{ }^{a} \\
\text { 검중 }\end{array}$} & \multirow{2}{*}{ 채택여부 } \\
\hline & & & & $\ln w$ & hioh & & \\
\hline $\mathrm{H} 5 \mathrm{a}$ & & & PK & $.36(5.57)$ & $.56(8.41)$ & $4.53 * *$ & 0 \\
\hline $\mathrm{H} 5 \mathrm{~b}$ & $\mathrm{Aad} \rightarrow \mathrm{Cb}$ & 811 & INV & $.54(7.67)$ & $.38(5,97)$ & 1.98 & $x$ \\
\hline $\mathrm{H} 5 \mathrm{c}$ & & & $\mathrm{PK} \times \mathrm{INV}^{\mathrm{b}}$ & $.56(8.42)$ & $.38(6.02)$ & $3.90 * *$ & 0 \\
\hline
\end{tabular}

$a: * p<.1, * * p<.05, * * * p<.01$

$\mathrm{b}: \mathrm{PK} \times \mathrm{INV}$ 는 각각 높은 사전지식 집단과 높은 관여도 집단 모델의 비교입

4.3.3.4 Ab와 $\mathrm{lb}$ 의 관계에 관한 조절효과 분석

가설 2에서 상표에 대한 감정적 평가가 상표에 대한 행동의욕적 평가에 유의적인 영향을 미치는 것으로 나타넜다. 이를 바탕으로 사전지식과 관여도의 역할을 살며보면 <표 9>와 같다.

<표 9> 사전지식과 관여도에 따른 $\mathrm{Ab} \rightarrow \mathrm{Ib}$ 경로의 $\mathrm{x}^{2}$ 차이 검중 졀과

\begin{tabular}{|c|c|c|c|c|c|c|c|}
\hline \multirow{2}{*}{ 가설 } & \multirow{2}{*}{ 경로 } & \multirow{2}{*}{ 경로명칭 } & \multirow{2}{*}{ 조절변수 } & \multicolumn{2}{|c|}{ 경로계수 ( $\mathrm{t}$ 값) } & \multirow{2}{*}{$\begin{array}{c}\mathrm{x}^{2} \text { 차이 }{ }^{\mathrm{a}} \\
\text { 검중 }\end{array}$} & \multirow{2}{*}{ 채택여부 } \\
\hline & & & & $\operatorname{lnw}$ & high & & \\
\hline $\mathrm{H} 6 \mathrm{a}$ & & & PK & $.65(12.18)$ & $.73(13.23)$ & 2.15 & $\times$ \\
\hline $\mathrm{H} 6 \mathrm{~b}$ & $A b \rightarrow I b$ & $\beta_{32}$ & INV & $.67(11.64)$ & $.70(13.47)$ & $4.91 * *$ & 0 \\
\hline $\mathrm{H} 6 \mathrm{c}$ & & & $\mathrm{PK} \times \mathrm{INV}^{\mathrm{b}}$ & $.65(11.78)$ & $.67(11.31)$ & .23 & $x$ \\
\hline
\end{tabular}

$\mathrm{a}: * \mathrm{p}<.1, * * \mathrm{p}<.05, * * * p<.01$

$\mathrm{b}$ : PKX INV는 각각 낮온 사전지식 집단과 낮은 관여도 집단 모댈의 비교입

가설 $6 \mathrm{a}$ 는 상표에 대한 감정적 평가에서 상표에 대한 행동의욕적 평가로의 영향력이 사전지식이 높은 집단보다 사전지식이 낮은 집단에서 더 클 것이라 예상하였다. 두 집단의 경로계수들의 비교 결과 영향력의 차이는 유의적이지 않은 것으로 나타났다. 관여도의 경우 관여수준이 높은 집단보다 낮은 집단에서 $\mathrm{Ab} \rightarrow \mathrm{Ib}$ 경로의 영향력이 더 클 것으로 예상하였는데 카이자승 검증결과 기대와 다르게 관여도가 높은 집단에서 더 큰 영향을 미치는 것으로 나타났다 $\left(\mathrm{x}^{2}=4.91, \mathrm{p}<.05\right)$, 따라서 가설 $\mathrm{H6a}, \mathrm{H6b}$ 는 지지되지 못하였다. 그러나 관여도의 효과는 선행연구(이재록 \& 이학식 1998)와 동일한 결과률 보여 이의 의미를 연구의 결과 및 시사점 부분에서 논의하였다. 한편, $\mathrm{Ab} \rightarrow \mathrm{Ib}$ 경로에 대한 사전지식과 관여도의 상대적 효과 비교는 사전지식이 낮은 집단과 관여도가 낮은 집단간에 유의적인 차이가 없는 것으로 나타나 가설 $\mathrm{H} 6 \mathrm{c}$ 는 지지되지 못하였다. 


\section{5. 연구결과 및 시사점}

본 연구는 광고에서 제공되는 정보들을 소비자가 인지적, 감정적 측면에서 어떻게 평가하는가를 인지와 감정의 통합적 시각에서 살펴보았다. 특히, 그 동안 가장 많은 연구가 진행되어 온 부분중의 하나인 광고에 대한 정보처리적 관점을 중심으로 능력의 관점인 사전지식과 정보처리동기의 관점인 관여도의 개별적 그리고 상호작용적 영향력을 이론적으로 검토하여 보았다. 이를 위하여 본 연구는 인지/감정 혼합광고를 소비자의 인지적 평가, 감정적 평가, 행동의욕적 평가로 분류하여 정보의 접근성과 진단성을 중심으로 사전지식과 관여도의 상대적 영향력을 고찰해 보았다. 연구결과를 요약하면 다음과 같다.

먼저, 광고에 대한 감정적 평가(Aad), 상표에 대한 감정적 평가(Ab), 상표에 대한 인지적 평가 $(\mathrm{Cb})$, 상표에 대한 행동의욕적 평가( $\mathrm{Ib})$ 간의 주 경로에 대한 효과는 모두 지지되는 것으로 나타났다. 그리고 이들 경로에 대한 사전지식과 관여도의 역할에 있어서는 먼저 사전지식의 경우 $\mathrm{Aad}$ 에서 $\mathrm{Cb}$ 로의 경로와 $\mathrm{Cb}$ 에서 $\mathrm{Ab}$ 로의 경로가 사전지식이 낮은 집단보다 높은 집단에서 더 강한 영향력이 있는 것으로 나타났다. 그러나 관여도의 경우에는 Aad에서 $\mathrm{Ab}$ 로의 경로와 $\mathrm{Ab}$ 에서 $\mathrm{Ib}$ 로의 경로에서 낮은 관여집단보다 높은 관여집단에서 더 큰 영향력이 있음을 발견하였다. 한편, 사전지식과 관여도의 상대적 효과에 대해서는 대부분의 경로에서 유의적인 차이률 보이지 않았으나 $\mathrm{Aad} \rightarrow \mathrm{Cb}$ 경로에 있어서 관여도가 높은 집단보다는 사전지식이 높은 집단에서 그 상대적 영향력이 더 큼을 알 수 있었다.

이와 같은 결과를 토대로 본 연구는 다음과 같은 의미를 제시할 수 있다.

첫째, 소비자들의 광고정보를 처리하는 과정에서 인지적 과정과 감정적 과정의 두 가지 경로를 통하여 태도가 형성된다는 사실은 그 동안 정교화 가능성 모형(ELM)이나 기타 이론들에 의해 많은 뒷받침이 되어 왔으나, 인지와 감정적 과정을 통합적인 시각에서 고찰하려는 노력들은 다소 미흡한 실정이다. 따라서 본 연구는 이러한 관점에서 소비자의 정보처리능력과 정보처리동기의 수준별로 인지적 평가와 감정적 평가의 상대적 영향력이 어떻게 달라질 수 있는가를 실증적으로 살펴보았다는 데에서 그 의의를 찾을 수 있다.

둘째, 연구의 실증결과에 따르면 광고에 대한 감정적 평가는 상표에 대한 감정적 평가에 직접적으로 영향올 미치고 또한 상표에 대한 인지적 평가를 통해 간접적으로도 영향력이 있음을 확인하였다. 이러한 결과는 선행 연구인 MacKenzie, Lutz and Belch(1986)의 $\mathrm{DMH}(\mathrm{Dual}$ Mediation Hypothesis) 모델과 일치한다. 즉, 소비자의 광고에 대한 감정적인 반응은 광고에서 제시하는 제품의 속성에 대한 주장을 받아들이려는 성향에 영향을 줄 수 있고, 따라서 광고자극에 대한 소비자의 감정적 반웅은 광고상표의 주장을 수용하는 데 영향을 미치며 결국 이는 상표에 대한 감정적 태도률 형성하는 데에도 영향을 미친다고 할 수 있다. 즉, 소비자가 광고에 대해 우호적인 감정올 많이 느낄수록 광고에서 주장하는 내용을 더 많이 수용한다고 볼 수 있다.

셋째, 광고에 대한 감정적 평가(Aad)에서 상표에 대한 인지적 평가 $(\mathrm{Cb})$ 로의 경로에서는 관여도와 사전지식이 낮은 집단보다 높은 집단에서 더 클 것으로 예상하였는데, 분석결과 관여도와 관련해서는 유의적인 차이를 발견하지 못하였으나 사전지식의 경우 지식수준이 높은 집단일수록 더 큰 영향력이 있는 것올 나타났다. 또한 관여도가 높은 집단과 사전지식이 높은 집단의 비교에서도 관여도보다는 사전지식의 상대적 효과가 더 큰 것을 알 
수 있었다. 따라서 $\mathrm{Aad}$ 에서 $\mathrm{Cb}$ 로의 경로의 경우 광고에 대한 정보처리능력이 큰 역할을 하는 것으로 해석된다.

넷째, 상표에 대한 인지적 평가 $(\mathrm{Cb})$ 와 상표에 대한 감정적 평가(Ab)의 관계는 $\mathrm{Aad} \rightarrow$ $\mathrm{Cb}$ 의 경로에서와 마찬가지로 관여도보다는 사전지식수준이 높은 집단에서 더 강한 영향력이 있는 것으로 나타넜다. 이는 광고에 대한 감정적 평가가 상표에 대한 인지적 평가를 통해 상표에 대한 태도(상표에 대한 감정적 평가)를 형성한다는 $\mathrm{DMH}$ 모델을 역시 실증적으로 뒷받침 해주고 있다. 또한 이러한 현상은 소비자가 제품의 속성에 대해 보다 주의 깊게 관찰하고 이를 토대로 중심경로(central route)를 통해 제품평가가 이루어진다는 ELM(Petty and Cacioppo 1981) 모델의 주장과도 일치한다. 따라서 상표에 대한 인지적 평가를 통해 상표에 대한 감정적 평가가 이루어지는 경우 소비자가 정보처리 능력이 클수록 광고메시지에 주의를 더 잘 기울이고, 제품정보를 이해하려고 애쓰며, 이률 통해 제품에 대한 평가가 더 지속적으로 이루어진다고 볼 수 있다.

다섯째, 광고에 대한 감정적 평가(Aad)는 상표에 대한 감정적 평가(Ab)에 직접적 영향을 미치게 되는데 그 영향력은 사전지식과 관여도가 낮은 집단에서 더 클 것으로 기대하였다. 그러나 분석결과 사전지식은 두 집단간에 유의적인 차이가 없었으나 관여도의 경우 기대와 다르게 관여도가 높은 집단에서 더 큰 영향력이 있는 것으로 나타났다. 이와 같은 결과는 저관여 소비자가 정교화 가능성이 낮아 주로 주변경로(peripheral route)에 의해서 정보처리가 이루어진다는 Petty, Cacioppo and Schumann(1983)의 주ㅈㅏㅏㅇㄱㅘ 배치되는 결과로서 이는 광고에 대한 감정적 평가가 고관여 소비자에게도 영향력이 있음을 의미한다. 이러한 연구결과는 고지식/고중요성 집단에서 광고에 대한 감정적 평가의 상표에 대한 감정적 평가로의 영향력이 매우 큰 것으로 나타난 Lutz, MacKenzie and Belch(1983)의 연구결과와 유사하다. 특히 본 연구에서는 광고에 대한 감정적 평가를 위해 지역정서소구를 이용하였다. 따라서 위와 같은 결과를 통해 유추해 보면 비록 지역정서소구가 반영된 광고라 할지라도 상표에 고관여된 소비자가 저관여된 소비자보다 $\mathrm{Aad} \rightarrow \mathrm{Ab}$ 로의 영향력이 더 크게 나타났기 때문에, 만약 위와 같은 유형의 광고에 소비자가 노출되었다면 지역정서와 관련된 감정의 영향력보다는 상표에 대한 개인적 관련성의 염향력이 더 크게 작용하는 것으로 해석할 수 있다(관여도수준에 따른 지역정서 차이: low involvement group(2.95) vs high involvement $\operatorname{group}(2.77), F_{1,358}=2.175, p=.141$ ).

마지막으로, 상표에 대한 감정적 평가 $(\mathrm{Ab})$ 와 상표에 대한 행동의욕적 평가(Ib)간의 관계에서는 상표에 대한 관여도가 높은 집단일수록 경로에 미치는 영향력이 더 큰 것으로 나타넜다. 이는 선행연구인 이재록과 이학식(1998)의 연구결과와도 일치하는 것으로서 소비자가 상표에 대한 감정적 평가를 할 때 보다 높은 관여도를 가지고 있는 소비자일수록 상표에 대한 행동의욕적 평가 또는 실제 행동에 더 큰 영향을 미치는 젓으로 기대할 수 있다. 이는 Berger and Mitchell(1989)의 고관여 상태에서 광고에 반복적으로 노출된 소비자의 태도가 직접경험에 의해 형성된 태도와 유사한 접근가능성과 태도자신감을 가지게 되고, 이에 따라 소비자의 상표에 대한 태도의 행동예측력올 더 높일 수 있다고 보는 견해와도 맥락을 같이한다.

본 연구는 실무 기업측면에서도 기업이 설득광고소구를 소비자에게 전달하고자 할 경우 광거되는 제품에 대하여 소비자 집단별 톡싱에 따라 차별적인 광고전략을 어떻게 수립해야 하며, 어떻게 설계하는 것이 소비자들을 보다 잘 설득할 수 있는가에 대한 하나의 지침을 제공해준다고 할 수 있다. 그러나 본 연구는 이러한 시사점에도 불구하고 본 연구가 세시한 
제 가설들을 보다 명확하게 살며보기 위해서는 다음과 같이 향후 이를 보완할 수 있는 보다 심층적인 연구가 뒷반침되어야 할 것으로 판단된다.

먼저, 본 연구는 이론적인 면에서 인지- 감정(태도) 행동으로 이어지는 태도의 단일차원적 견해에 입각하여 이론을 전개하였다. 그러나 주지하는 바와 같이 이러한 모델은 주로 고관여상황에서 전개되는 모델이다. 따라서 관여도가 낮다든지 또는 감정이 강하게 지배하는 소비상황의 경우에는 다른 과정이 가능하다는 것이 랋은 선행연구들에서 제시되어오고 있다(즉, Krugman의 저관여모델이나 Zajonc의 단순노출모델 둥). 따라서 향후 연구에서는 저관여상태에서의 태도변화는 어떠한 요소들이 영향을 미칠 수 있는가의 검토가 필요하다.

둘째, 본 연구는 실헙대상 제품의 선정에 있어서 비교적 피실험자들이 많은 관심올 가지고 있는 제품이면서도 지식수준의 측정이 용이하다고 판단되는 컴퓨터를 가지고 수행하였다. 그러나 실험대상제품이 매우 고관여된 제품이기 때문에 피헙자들의 전반적인 관여도가 매우 높게 나타나 있고 이에 따라 비록 관여도의 전체평균 점수를 가지고 상대적으로 낮은 집단과 높은 집단의 영향력울 살펴보았음에도 불구하고 관여도의 상대적 효과률 충분히 검토하지 못했다는 한계점이 있다. 그리고 이러한 한계점은 본 연구의 실중결과에서 사전지식과 관여도의 상대적 효과들이 많은 차이를 보이지 못한 이유가 될 수도 있다. 따라서 향후 이 분야에 대한 보다 정교화된 연구들을 위해서는 제품선정시 저관여된 제품도 같이 선정하여 각 제품에 따른 관여도의 효과를 보다 면밀히 검토해 볼 필요가 있다. 아울러 이러한 점은 사전지식수준의 고려에도 합께 적용되어야 할 것으로 판단되며, 본 연구률 계기로 향후 이 분야에 대한 연구가 보다 활발히 수행되기률 기대한다.

셋째, 실헙상황의 설정시 인쇄된 광고물과 빔프로젝터에 의한 시각적 정보에 의존하였는데 실험상황을 보다 현실화하기 위해서는 다수의 삽입광고들을 표적광고와 함께 제시함으로써 보다 실제적인 실험설계가 이루어져야 할 것으로 판단된다. 아울러 본 연구에서는 인지적 요소와 감정적 요소를 동시에 포함한 하나의 광고를 보여주고 소비자들의 반웅을 측정하였는데, 향후 연구에서는 인지적 요소률 강조한 광고와 감정적 요소를 강조한 광고를 달리 하여 소비자의 광고태도를 측정해 봄으로써 보다 다양한 감정적 소구들에 따른 소비자 반웅들을 검토해 볼 필요가 있다.

넷째, 광고노출에 대한 태도의 형성은 노출 직후뿐만 아니라 일정한 시간이 지나면서 지속적으로도 형성된다. 그러나 본 연구는 광고노출 직후의 시점에서만 상표태도와 인지적 평가 그리고 구매의도간의 관계률 다루고 있다. 따라서 보다 실제적인 소비자 행동패턴을 이해하기 위해서는 광고노출 후 일정한 시간이 지난 후의 태도를 비교 측정함으로써 광고에 대한 평가와 상표에 대한 평가 그리고 상표에 대한 구매의도간의 관계를 파악해 볼 펄요가 있다. 


\section{<참고문헌>}

김완석(1993), “소비자의 감정적 반응과 광고효과 과정: 유형별 차이와 개인차,"

광고연구, 겨울호, 31-70.

김완석(1995), "톡정 감정에 소구하는 광고의 효과기재," 광고연구, 가을호, 9-34.

이재록, 이학식(1998), “ 광고효과 단계에 있어서 평가목표, 관여도, 태도자신감의 초절적

작용," 마캐팅연구, 13(2), 53-76.

이학식(1991). “정서적 반웅이 광고효과에 미치는 영향: 제품소비경험과 관여도의 조정적

역할," 경영학연구, 21(1), 345-367.

이학식, 김종성(1999), “상표확장효과의 조절변수로서 소비자 특성과 지각의 역할평가,"

마케팅연구, 14(2), 23-44.

이학식, 정주혼, 이호배(1998), “광고효과의 조절변수로서 인지욕구과 감성강도의 평가,"

마케팅연구, 13(1), 105-131.

Ahluwalia, R. and Zeynep Gurhan-Canli(2000), “ The Effects of Extensions on the Family

Brand Name: An Accessibility-Diagnosticity," Journal of Consumer Research, 27(December), 371-381.

Alba, Joseph W. and J. Wesley Hut chinson(1987), "Dimensions of Consumer Expertise,"

Journal of Consumer Research, 13(March), 411-454.

Bagozzi, R. P.(1981), "Causal Modeling: A General Method for Developing and Testing

Theories in Consumer Research," Advances in Consumer Research, 8, 195-202.

Bat ta, R. and M. L. Ray (1986), " Af fect ive Responses Mediat ing Accept ance of Advert ising, " Journal of Consumer Research, 13(September), 234-249.

Belch, George E. (1981), "The Effects of Television Commercial Repetition on Cognitive Response and Message Acceptance," Journal of Consumer Research, 9(June), 56-65.

Berger, Ida E. and Andrew A. Mitchel1(1989), “ The Effect of Advertising on Attitude Accessibility, Attitude Confidence, and Attitude-Behavior Relationship, "Journal of Consumer Research, 16(December), 269-279.

Brucks, Merrie(1985), "The Effects of Product Class Knowledge on Information Search Behavior," Journal of Consumer Research, 12(June), 1-16.

Brucks, Merrie.(1986), "A Typology of Consumer Knowledge Content," in Advances in Consumer Research, 13, ed. Richard J. Lut z, Provo, UT: Association for consumer Research, 58-63.

Burke, M. C. and J. A. Edell(1989), "The Impact of Feelings on Ad-based Affect and Cognition," Journal of Marketing Research, 26(February), 69-83.

Celsi, R. L. and J. C. Olson(1988), "The Role of Involvement in Attention and Comprehension," Journal Consumer Research, 15(September), 210-224.

Chaiken, S. (1980), "Heuristic versus Systemat ic Informat ion Processing and the Use of Source ver sus Message Cues in Persuasion, "Journal of Personal ity and Social Psychology, $39(5), 752-766$.

Duncan, Calvin P. and Richard W. Ol shavsky(1982), " External Search: The Role of Consumer Beliefs," Journal of Marketing Research, 19(February), 32-43. 
Feldman, J. M. and J. G. Lynch(1988), "Self-Generated Validity and Other Effects of Measurement on Belief, Attitude, Intention, and Behavior," Journal of Applied Psychology, 73, 421-435.

Fishbein, M., (1963), "An Investigation of the Relationships Beliefs about an Object and the Attribute Toward the Object," Human Relations, 16, 233-240.

Fishbein, M. and Icek Ajzen(1975), Belief, Attitude, Intent ion and Behavior, Reading, MA: Addison-Wesley Publishing Company.

Fornell, Claes and David F. Larcker(1981), "Evaluat ing Structural Equation Models with Unobservable Variables and Measurement Error," Journal of Marketing Research, 18(February), 39-50.

Friestad, M. and E. Thorson(1986), "The Effects of Emotion on Recall and Evaluation of Televised Promotional Messages," Unpublished Manuscript, Madison: University of Wisconsin.

Gardner, Meryl P. (1985), “ Does At t itude Toward the Ad Af fect Brand At t itude Under a Brand Evaluat ion Set?" Journal of Marketing Research, 22(May), 192-198.

Gerbing, David A. and James C. Ander son(1988), " An Updated Paradigm for Scale Development Incorporat ing Unidimensional ity and Its Assessment, " Journal of Market ing Research. 25(May), 186-192.

Golden, L. L., and K. A. Johnson(1983), "The Impact of Sensory Preference and Thinking versus Feeling Appeals on Advertising Effectiveness," in R. P. Bagozzi and A. M. Tybout(Eds), Advances in Consumer Research, 10, 203-208.

Greenwald, A. G. (1968), "Cognitive Learning, Cognitive Response to Persuasion and At t itude Change," in A. G. Greenwald, T. B. Brock and T. M. Ostrom(Eds.), Psychological Foundations of Attitudes, N.Y. Academic Press.

Greenwald, A. G. and C. Leavitt(1984), "Audience Involvement in Advertising: Four Levels," Journal of Consumer Research, 11(June), 581-592.

Grunert, Klaus G.(1996), "Automatic and Strategic Processes in Advertising Effects," Journal of Marketing, 60(October), 88-101.

Hair, Josph F., Rolph E. Anderson Ronald L, Tatham, and William C. Black(1995), Multivariate Data Analysis with Readings, 4th ed., Prentice-Hall, Englewood $\mathrm{Cl}$ iffs, New Jersey

Herr, Paul M., Frank R. Kardes, and JOhn Kim(1991), "Effects of Word-of-Mouth and Product-Attrubute Information on Persuasion: An Accessibility-Diagnosticity Perspect ive," Journal of Consumer Research, 17(March), 454-462.

Hill, R. P. and M. B. Mazis(1986), "Measuring Emotional Responses to Advertising," in R. J. Lutz(Ed), Advances in Consumer Research, 13, 164-169, Provo, UT: Association for Consumer Research.

Houston, M. J. and M. L. Rothschild(1978), " Conceptual and Methodological Perspectives in Involvement," in: S. Jain(ed.), Research Frontiers in Marketing: Dialogues and Directions, 184-187, Chicago, IL: American Marketing Association.

Johnson, E. and J. E. Russo(1984), "Product Familiarity and Learning New Information," 
Journal of Consumer Research, 11(June), 542-550.

Jonathan, Gutman(1982), “A Means-End Chain Model Based on Consumer Categorization Processes," Journal of Marketing, 46(Spring), 60-72.

Jō reskog, Karl and Dag. Sö rbom(1999), LISREL 8.30: Structural Equat ion Model ing wi th the SIMPLIS Command Language.

Kardes, F. R. (1988), "Spontaneous Inference Processes in Advert ising: The Effects of Conclusion Omission and Involvement on Persuasion," Journal of Consumer Research, 15(September), 225-233.

Krugman, H. E.(1965), "The Impact of Television Advertising: Learning without Involvement," Public Opinion Quarterly, 29(Fall), 349-356.

Krugman, H. E. (1977), "Memory without Recal1, Exposure wi thout Percept ion," Journal of Advert ising Research, 17(4), 7-12.

Lut z, R. J.(1985), "Affective and Cognitive Antecedents of Attitude toward the Ad: A Conceptual Framework," In: L. Alwitt and A. Mitchell (eds.), Psychological Processes and Advertising Effects, 45-65. Hillsdale, NJ: Lawrence J. Erlbaum.

Lynch, John G. Jr. . H. Marmorstein, and M. F. Weigold(1988), "Choices from Sets Including Remembered Brands: Use of Recalled Attributes and Prior Overall Evaluat ions, "Journal of Consumer Research, 15(September), 225-233.

MacKenzie, Scot t B. and Richard A. Spreng(1992), "How Does Mot i vat ion Moderate the Impact of Central and Peripheral Processing on Brand Attitudes and Intentions?," Journal of Consumer Research, 18(March), 519-529.

MacKenzie, S. B., R. J. Lutz and G. E. Belch(1986), "The Role of At titude toward the Ad as a Mediat ion of Advert ising Ef fect i veness: A Test of Compet ing Explanat ions, "Journal of Market ing Research, 23(May), 130-143.

Marks, L. J. and J. C. 01son(1981), "Toward a Cognit ive Structure Conceptual izat ion of Product Familiarity, " In: K. Monroe(ed.), Advances in Consumer Research, 8, 145-150. Mitchell. Andrew A. and Jerry C. Olson(1981), "Are Product Attribute Beliefs the Only Mediator of Advertising Effects on Brand Attitude?" Journal of Marketing Research, 18(August), 318-332.

Okechuku, Chike(1992), "The Relationships of Prior Knowledge and Involvement to Advertising Recall and Evaluation," International Journal of Research in Marketing, 9, 115-130.

Park, C. W. and V. P. Lessig(1981), "Familiarity and its Impacts on Consumer Decision Biases and Heuristics," Journal of Consumer Research, 8(September), 223-230.

Park, C. Whan, David L. Mothersbaugh and Lawrence Feick(1994), " Consumer Knowledge Assessment," Journal of Consumer Research, 21(June), 71-82

Park, C. Whan and S. Mark Young( 1986), "Consumer Response to Televi sion Commercials: The Impact of Involvement and Background Music on Brand Attitude Format ion," Journal of Market ing Research, 23(February), 11-24.

Petty, Richard E., John T. Cacioppo(1979), "Issue Involvement Can Increase or Decrease Persuasion by Enhancing Message-relevant Cognit ive Responses, " Journal of Personality 
and Social Psychology, 37(10), 1915-1926.

Pet ty, Richard E., John T. Cacioppo(1981), "Issue Involvement as Moderator of the Ef fects on At titude of Advert ising Content and Context," in Advances in Consumer Research, 8, Ed. Kent B. Monroe, Ann Arbor, MI: Association for Consumer Research, 20-24.

Pet ty, Richard E., John T. Cacioppo, and David Schumann(1983), "Central and Peripheral Routes to Advert ising Ef fect iveness: The Moderat ing Role of Involvement, " Journal of Consumer Research, 10(September), 135-146.

Rao, Akshay R. and Kent B. Monroe.(1988), " The Moderat ing Effect of Prior Knowledge on Cue Ut i lizat ion in Product Evaluat ions," Journal of Consumer Research, 15 (September), 253-264.

Rao, Akshay R. and Wanda A. Sieben. (1992), "The Effect of Prior Knowledge on Price Acceptability and the Type of Informat ion Examined," Journal of Consumer Research, 19(September), 256-270.

Richins, M. L. and P. H. Block(1986), "After the New Wears Off: The Temporal Context of Product Involvement," Journal of Consumer Research, 13(Sept ember), 280-285.

Sujan M. (1985), "Consumer Knowledge : Effects on Evaluation Strategies Mediating Consumer Judgments," Journal of Consumer Research, 12(June), 31-46.

Zaichkowsky, Judith L.(1985a), "Measuring the Involvement Construct," Journal of Consumer Research, 12(December), 341-352.

Zaichkowsky, J. L. (1985b), "Familiarity: Product Use, Involvement or Expert ise?," In: E.C. Hirschman and M.B. Holbrook (eds.), Advances in Consumer Research, 12, 296-299, Provo, UT: Association for Consumer Research.

Zaichkowsky, J. L.(1994), "The Personal Involvement Inventory: Reduction, Revision, and Application to Advert ising," Journal of Advertising, 15(2), 4-14.

Zinkhan, G. M. and A. Muderrisoglu(1985), " Involvement, Familiarity, Cognitive Differentiation, and Advertising Recall: A Test of Convergent and Discriminant Val idity," In: E.C. Hirschman and M. Holbrook (eds.), Advances in Consumer Research, 12, 356-361, Provo, UT: Association for Consumer Research. 